\title{
Linkages between Summer Rainfall Variability over South America and Sea Surface Temperature Anomalies
}

\author{
Julia N. PAegle \\ Department of Meteorology, University of Utah, Salt Lake City, Utah \\ Kingtse C. Mo \\ Climate Prediction Center, NCEP/NWS/NOAA, Camp Springs, Maryland
}

(Manuscript received 30 April 2001, in final form 5 December 2001)

\begin{abstract}
A reconstructed rainfall dataset, and satellite estimates are used to analyze interannual to decadal variability of austral summer precipitation over South America. Rotated empirical orthogonal function (REOF) analysis is applied to isolate dominant patterns of rainfall. Links of these patterns to sea surface temperature anomalies (SSTAs) are examined.

The leading mode is related to El Niño-Southern Oscillation (ENSO), which explains $12 \%$ of the total variance. During warm ENSO events, the positive phase of this mode shows dry conditions over northern South America and wet conditions over the subtropical plains between $25^{\circ}$ and $35^{\circ} \mathrm{S}$. The situation reverses during cold events. The second REOF 2, which explains about $10.8 \%$ of the total variance, consists of positive loadings over northeast Brazil centered at $50^{\circ} \mathrm{W}$ near the equator and negative loadings over Colombia and the subtropical plains. For December-January-February (DJF), REOF 2 is influenced by tropical South Atlantic SSTAs through displacements of the intertropical convergence zone. Northeast Brazil receives most rainfall in March-AprilMay (MAM) and it is modulated by both the Atlantic SSTAs and ENSO. In the interannual frequency band, the North Atlantic Oscillation (NAO) has very limited influence on rainfall. On the decadal timescales, the NAO leads REOF 2 by three years.

Latitudinal variations of tropical convection are through the joint contribution of REOF 2 and REOF 4. REOF 4 is similar to REOF 2, but centers are displaced about $10^{\circ}$ south. When these two EOFs are both positive, central South America is wet. The amplitudes of REOF 2 and REOF 4 are small during the mid-1950s to the mid-1960s and they are out of phase from 1968 to 1970, periods with persistent dry conditions over the upper La Plata River basin.
\end{abstract}

\section{Introduction}

This paper has two main objectives. The first is to show the dominant continental patterns of precipitation variability of austral summer from interannual to decadal timescales. This differs from most published work focusing on specific regions. The summaries of relevant work for the Amazon basin can be found in Marengo et al. (2001) and Fu et al. (1999). Rusticucci and Penalba (2000) reviewed the rainfall variability over southern South America. The second objective is to determine the extent to which these continental patterns might be linked to sea surface temperature (SST) variability. This subject has been addressed by several studies in a regional basis. For example, the influence of the tropical Pacific and Atlantic SSTs has been discussed for rainfall

Corresponding author address: Kingtse Mo, Climate Prediction Center, NCEP/NWS/NOAA, 5200 Auth Rd., Camp Springs, MD 20746.

E-mail: kingtse.mo@noaa.gov over northeast Brazil (see Uvo et al. 1998 for a review) and for the Amazon basin (Liebmann and Marengo 2001; Fu et al. 1999). Diaz et al. (1998) examined precipitation over the southeast region of South America including southern Brazil and Uruguay, a region with a strong El Niño-Southern Oscillation (ENSO) modulation (Ropelewski and Halpert 1987, 1989). They found links between SST anomalies (SSTAs) in the southwestern Atlantic Ocean and rainfall in this region. In contrast, our current focus is on SST links to continental modes, rather than regional patterns of precipitation.

Most of tropical and subtropical South America receives more than $50 \%$ of its annual precipitation in the austral summer from December to February (Gandu and Silva Dias 1998). Kousky (1988) documented the climatological onset of summer rainfall based on outgoing longwave radiation (OLR) and showed a general northwest to southeast progression of this onset. This progression is represented by the straight line in Fig. 1a with the precipitation seasonal march shown in Fig. $1 b$. Figure 1a also shows the location of a convective pre- 
(a)

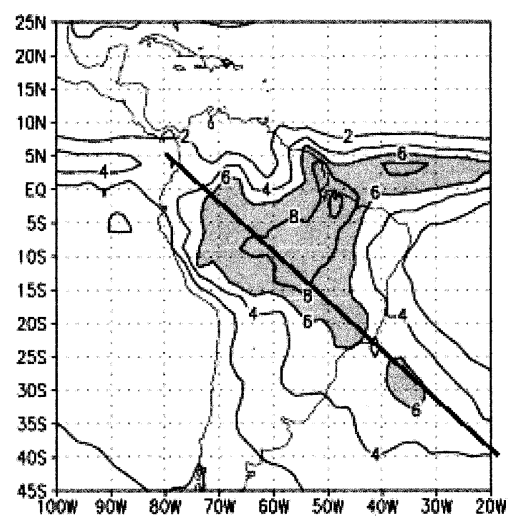

(b)

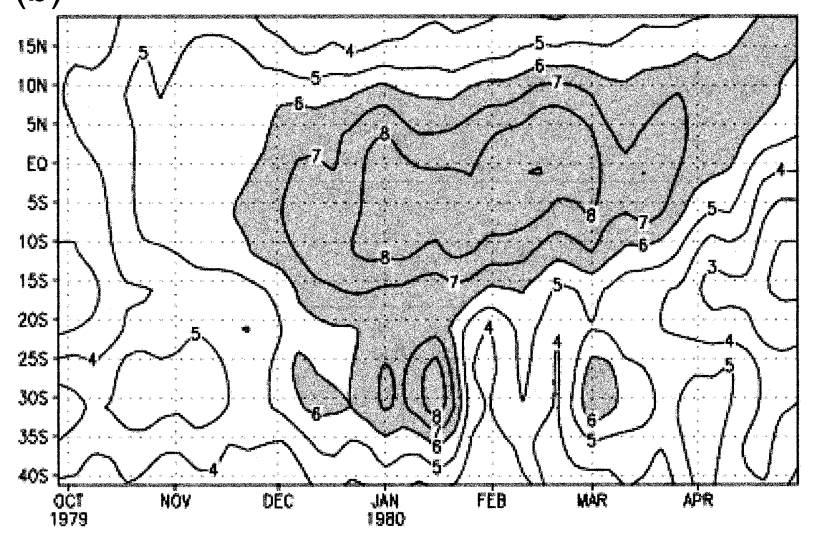

(c)

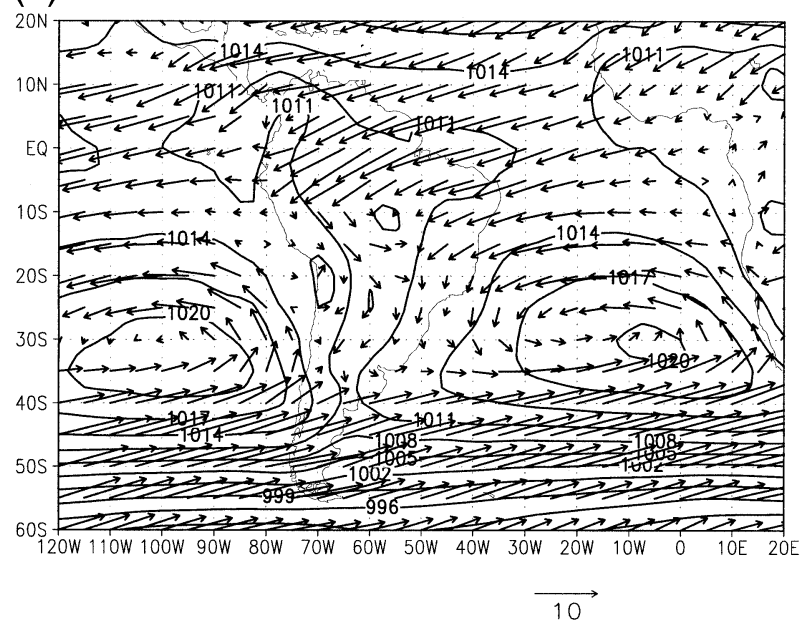

FIG. 1. (a) Climatological mean of precipitation averaged from Dec to Mar for 1979-99. Contour interval is $2 \mathrm{~mm} \mathrm{day}^{-1}$. Values greater than $6 \mathrm{~mm} \mathrm{day}{ }^{-1}$ are shaded, and (b) the climatological pentad mean of rainfall following the dark line in (a). The $y$ axis denotes the latitudes along the path. Contour interval is $1 \mathrm{~mm}$ day $^{-1}$. Values greater than $6 \mathrm{~mm}$ day $^{-1}$ are shaded, and (c) climatological SLP (contours) and $850-\mathrm{hPa}$ winds (vector). Contour interval is $3 \mathrm{hPa}$ and the unit vector is $10 \mathrm{~m} \mathrm{~s}^{-1}$. cipitation band [the South Atlantic convergence zone (SACZ)] extending from the center of the tropical continent toward the southeast in summer reaching the Atlantic Ocean at subtropical latitudes. This band modulates the intensity and location of summer rain. Figure $1 \mathrm{~b}$ shows precipitation of more than $6 \mathrm{~mm} \mathrm{day}^{-1}$ in the deep Tropics (north of $15^{\circ} \mathrm{S}$ ) from December to March. This period is chosen to depict the climatology.

Mean circulation at low levels over South America from December to March is shown in Fig. 1c by the 50 -yr climatological mean of sea level pressure (SLP) and $850-\mathrm{hPa}$ wind from the National Centers for Environmental Prediction-National Center for Atmospheric Research (NCEP-NCAR) reanalysis. A unique feature of the South American climate is a semipermanent continental low, found in summer between $20^{\circ}$ and $30^{\circ} \mathrm{S}$ east of the Andes (Gran Chaco low) and it is displaced $5^{\circ}-10^{\circ} \mathrm{N}$ and weaker during winter. The Chaco low is well developed during summer, with a strong thermal component resulting from the combination of high insolation and dry surface conditions. The resulting pressure gradient between the south Atlantic subtropical high and the Chaco low favors northeasterly flow and related moisture fluxes from the Atlantic into the continent. Pronounced pressure fall in the Gran Chaco area starts early in spring in response to rapid surface heating, while to the east and southeast pressure fall is weaker and more typical of maritime regimes. This results in a stronger pressure gradient force directed toward the continent in summer than in winter.

Moisture flux over the continent is regulated by easterly trade winds resulting from the equatorial branches of the North and South Atlantic subtropical highs. Variations in location and intensity of the South Atlantic subtropical highs and concomitant SST variability also influence the South American climate. Nearby subtropical warm SST in the South Atlantic has been associated with increased precipitation over southeast South America (Barros et al. 1999). Remote Atlantic influences also have an impact on precipitation over South America. Hastenrath and Greischar (1993) and Hastenrath and Heller (1977) pointed out the relationships between South American rainfall and SST variations in the tropical Atlantic. Namias (1972) linked droughts in northeast Brazil to cyclonic activity in the Newfoundland and subtropical Atlantic anticyclone over the Northern Hemisphere. His composite of circulation anomalies resembles the North Atlantic Oscillation (NAO) teleconnection pattern. Northern South America is also influenced by the Pacific, with dry (wet) conditions during warm (cold) ENSO events (Aceituno 1988; Ropelewski and Halpert 1987, 1989). These studies suggest a complex system of processes influencing precipitation over South America.

This paper documents the summer precipitation regimes on the interannual and decadal timescales over South America. Rainfall regimes are then related to global SSTs. The paper is organized as follows: section 
2 describes data used, section 3 presents climatological averages, while section 4 focuses on interannual variations. Conclusions are given in section 5 .

\section{Data}

The data used in this study are monthly mean fields from the NCEP-NCAR reanalysis for the period from 1 January 1949 to 31 March 2000 (Kalnay et al. 1996). The data are on a $2.5^{\circ} \times 2.5^{\circ}$ latitude-longitude grid with 18 levels in the vertical. The seasonal cycle is defined as the monthly mean climatology at each grid point. Anomalies are defined as departures of monthly values from the seasonal cycle.

SSTs were reconstructed using empirical orthogonal functions (EOFs; Smith et al. 1996, 1998). The reconstruction was based on the historical data obtained from the Met Office. There are two reconstructed SST datasets. One set has a coarse resolution of $6^{\circ}$, but it covers the period from 1900 to 1998 . Another set has the resolution of $2^{\circ}$, and covers the recent period from 1950 to 1978. After 1979, SSTs were derived from the in situ and satellite data using the optimum interpolation method of Reynolds and Smith (1994). Climatological monthly means were removed from each dataset to obtain SSTAs before merging.

There are two precipitation datasets used here. One is the reconstructed rainfall data based on gauge observations from 1948 to 2000 on a $2.5^{\circ}$ grid (Chen et al. 2002; obtained through anonymous ftp online at ftp.ncep.noaa.gov/pub/precip/50yr/gauge/ $2.5 \mathrm{deg}$ ). The optimal interpolation scheme developed by Gandin (1965) was used to derive monthly mean precipitation from the station gauge data archived by the Climate Anomaly Monitoring System (Ropelewski et al. 1985) and the Global Historical Climatology Network (GHCN) version 2. This dataset will be referred to as the gauge dataset. The second dataset was obtained from merging satellite-derived precipitation estimates (Janowiak and Xie 1999) after 1979 with the precipitation dataset ftpd from Dr. Michael Hulme's Web page (Hulme 1991) at the Climate Research Unit, the University of East Anglia, United Kingdom, from 1900 to 1978. Climatological monthly means for each dataset were obtained and removed separately before merging. This dataset will be referred as the merged dataset. Most computations were performed using both datasets and the differences are discussed.

The monthly mean NAO index (Hurrell 1995; Hurrell and van Loon 1997) based on normalized SLP between Lisbon, Portugal, and Stykkisholmur/Reykjavik, Iceland, from 1864 to 2000 was obtained from the NCAR Web site.

\section{Climatology}

The climatological mean for summer (DecemberMarch) using the satellite pentad dataset from 1979 to
1999 (Janowiak and Xie 1999; Fig. 1a) shows the intertropical convergence zone (ITCZ) over the Atlantic extending into the center of the tropical continent. This average smooths out differences in the seasonal march of precipitation in the continent and the ITCZ. Continental precipitation shows a shift of convection from northeastern South America to southeastern subtropical South America from austral spring to the peak of the summer months (Horel et al. 1989; Kousky and Ropelewski 1997). The ITCZ maximum responds slowly to the seasonal migration of the sun. While the continental precipitation retreats northward during austral fall (March-April), the ITCZ continues to move southward, but stays north of $5^{\circ} \mathrm{S}$ (Zhou and Lau 2001). During spring, rainfall extends in a band from about $10^{\circ} \mathrm{N}$ to $10^{\circ} \mathrm{S}$ from Colombia toward the center of the continent. As the season progresses, rainfall shifts south of the equator into the subtropics and reaches a maximum in January (Fig. 1b). This seasonal march is typical of continental tropical precipitation regimes, with heaviest rain occurring when the sun is at its high point. Another maximum appears in December. It is centered at about $30^{\circ} \mathrm{S}$ over the Atlantic branch of the SACZ. This region experiences a break during February as shown by the minimum between the January and the March maxima. After the February break, rainfall increases. Synoptic frontal systems contribute to rainfall throughout the year in this region (Kousky 1979).

\section{Interannual variability}

The interannual variations of rainfall are determined through rotated empirical orthogonal function (REOF) analysis on the seasonal [December-January-February (DJF)] rainfall anomalies for the 1950-99 period. Calculations were performed for both precipitation datasets. The domain covers the land areas of South America $\left(45^{\circ} \mathrm{S}-15^{\circ} \mathrm{N}, 30^{\circ}-90^{\circ} \mathrm{W}\right)$. The first two EOFs and REOFs are the same. The high-order EOFs have smaller spatial scales and are not physically meaningful because of orthogonality. To avoid degeneracy, rotated EOFs were obtained using the Varimax rotation (Richman 1986; Richman and Lamb 1985). There are eight EOFs entering the Varimax rotation. The number of EOFs entering the rotation was determined based on the criterion by O'Lenic and Livezey (1988). The rotation relaxes the orthogonality and the rotated patterns are more similar to the teleconnection patterns (Barnston and Livezey 1987). The first four REOFs from the merged Humesatellite dataset are plotted in Figs. 2a-d. After obtaining REOFs, the data from 1900 to 1998 were projected onto REOFs to obtain rotated principal components (RPCs). Time series of RPCs are shown only from 1949 onward in Fig. 3, because the merged dataset has many missing data points before 1950 and the gauge dataset starts from 1948. RPCs before 1949 are used only to indicate longterm trends and decadal variability.

Calculations were repeated for the gauge dataset. 
a)reof $112 \%$

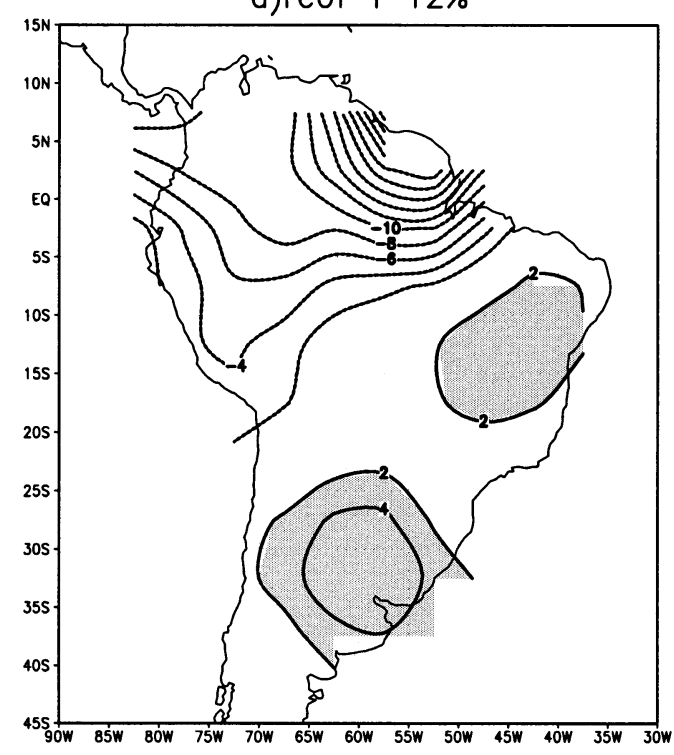

c)reof $38.1 \%$

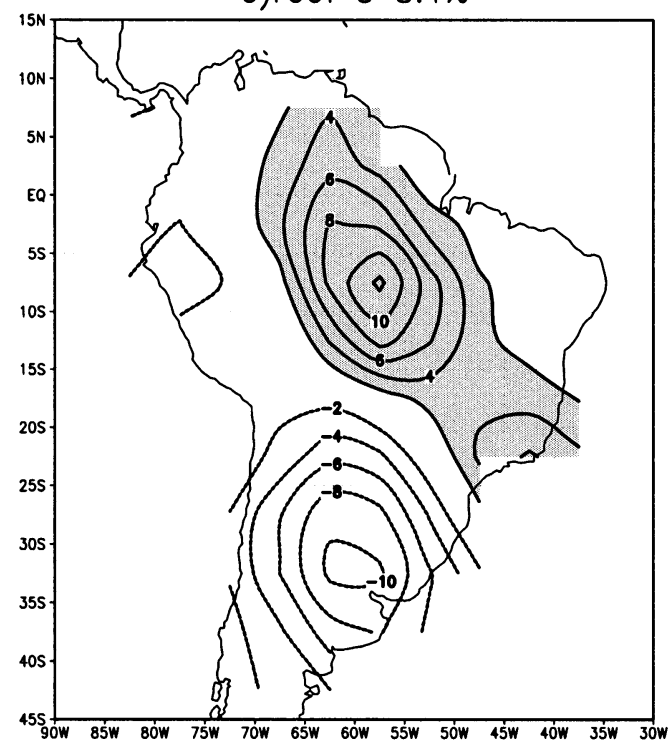

b)reof $210.8 \%$

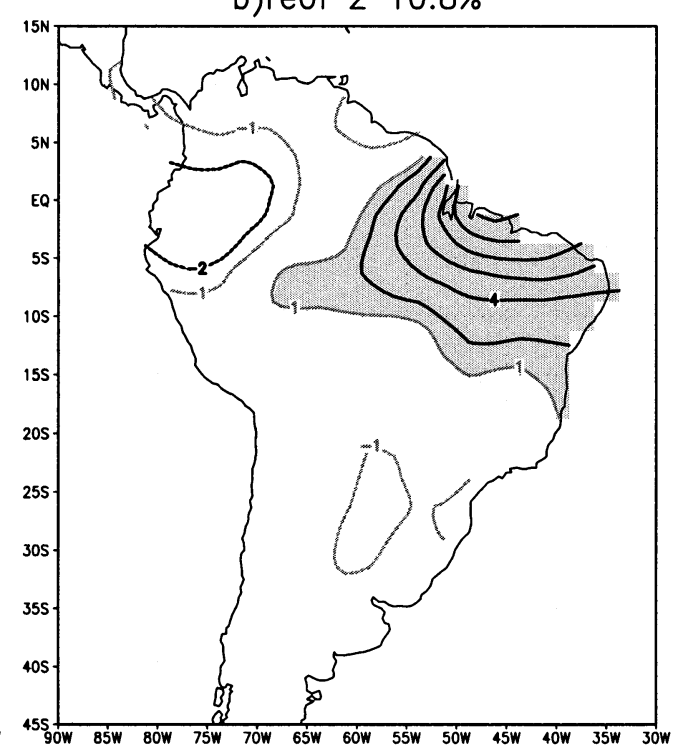

d)reof $47.2 \%$

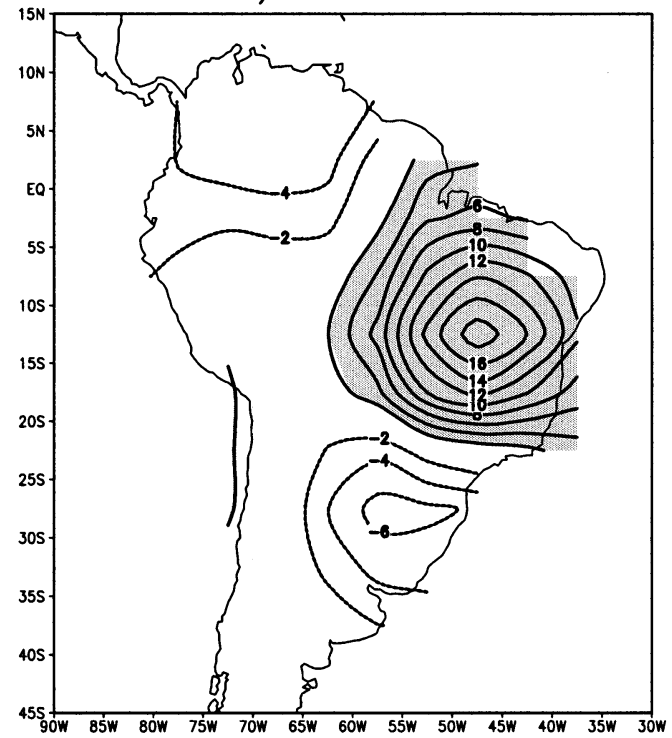

FIG. 2. (a) REOF 1, (b) REOF 2, (c) REOF 3, and (d) REOF 4 for DJF rainfall over South America from the merged dataset. Contour interval is 2 nondimensional units. Zero contours are omitted. Contours -1 and 1 are added for (b). The percentage at the top of each panel is the percent of the total variance explained by the REOF.

REOF 1 is the same and the correlation of RPC 1 between two time series is 0.98 . REOF 2 from the merged set appears as REOF 3 from the gauge dataset and the correlation between the corresponding RPCs is 0.95 (Fig. 3b). REOF 3 does not reproduce in the gauged dataset. REOF 4 from the gauge dataset (not shown) has some resemblance to REOF 3 from the merged set (Fig. 2c), but the correlation between two respective RPCs is only 0.83 . RPC 4 (merged set) is REOF 3 for the gauge dataset (Fig. 2d) and the correlation between two corresponding RPCs is 0.95 . REOF 1,2 , and 4 appear in both datasets. They are robust and are independent on the rainfall datasets used. The corresponding RPCs from two sets track each other well. REOF 3 does not reproduce in the gauge data. We will not discuss it further.

Correlations of RPCs with SSTAs from 1950 to 1999 are shown in Fig. 4. RPCs from both datasets show similar correlation patterns with no statistically significant differences between them. Each season is consid- 
a) RPC 1
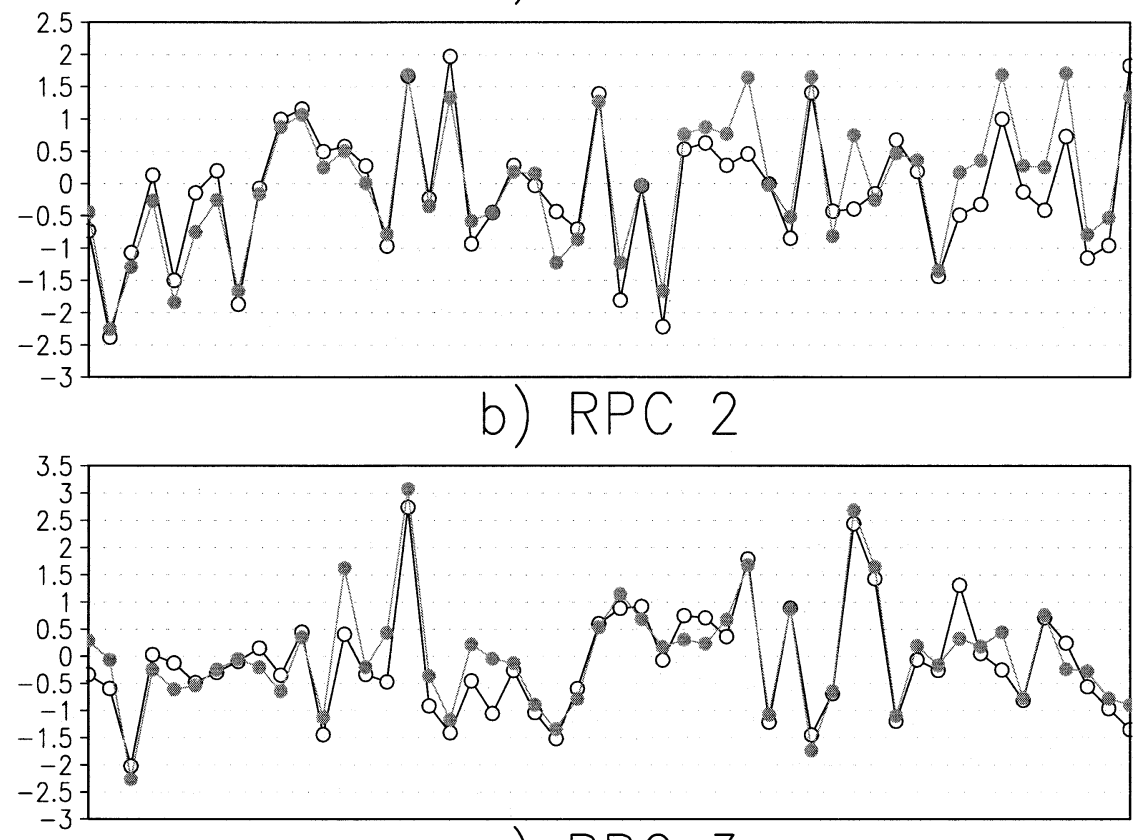

c) $\mathrm{RPC} 3$
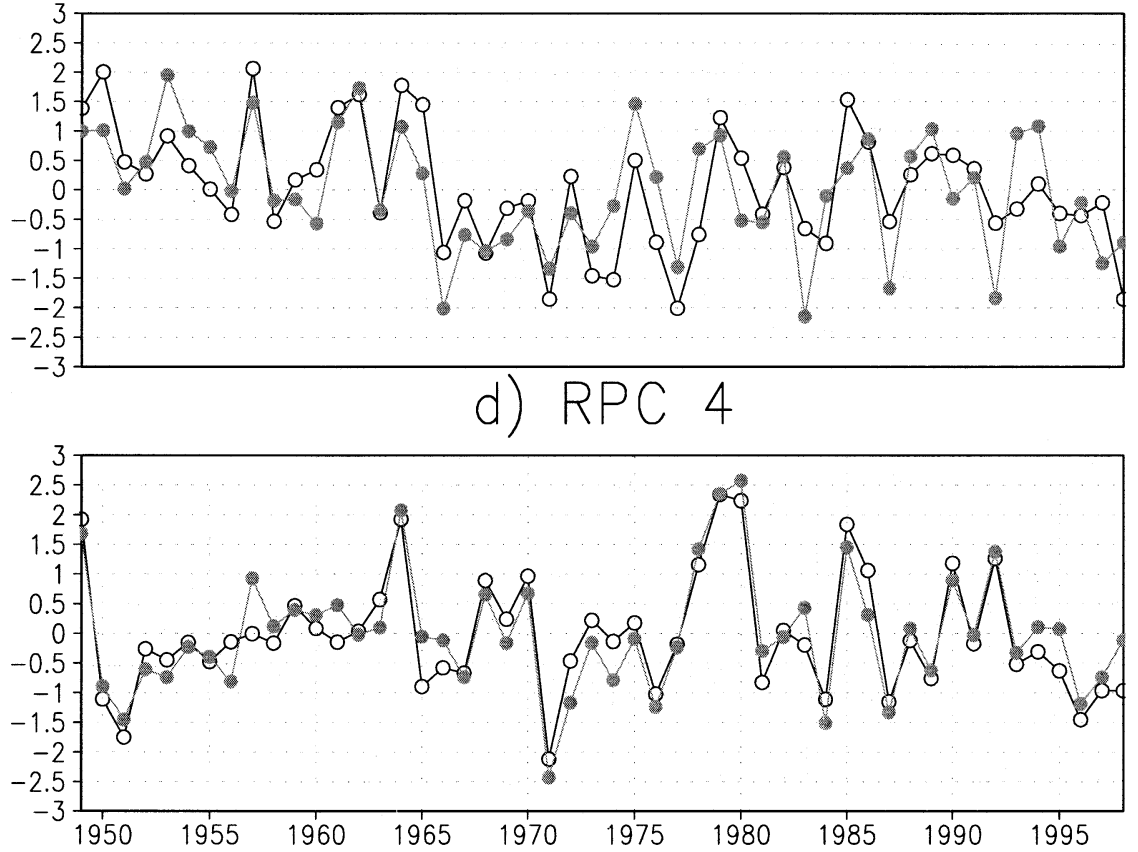

FIG. 3. Normalized (a) RPC 1, (b) RPC 2, (c) RPC 3, and (d) RPC 4 for merged rainfall dataset (open circles) and the corresponding RPCs from the gauge dataset (dark circles).

ered to represent 1 degree of freedom, and therefore values greater than $0.28(0.23)$ are statistically significant at the $95 \%$ (90\%) level.

Positive (negative) events were selected when a given RPC for DJF is greater than (less than) 1 (minus 1) standard deviation. Seasonal or monthly precipitation and circulation anomalies were then composited for positive and negative events from seasons (months) before to seasons (months) after DJF. When the composites for positive and negative events are similar with a sign reversal, the differences between positive and negative events are given to enhance the signal. Statistical sig- 
a) RPC 1

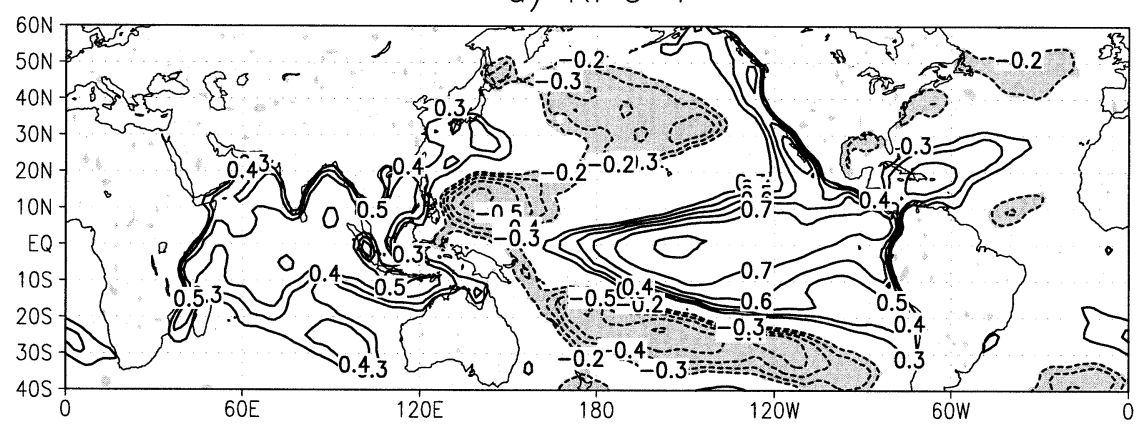

b) RPC 2

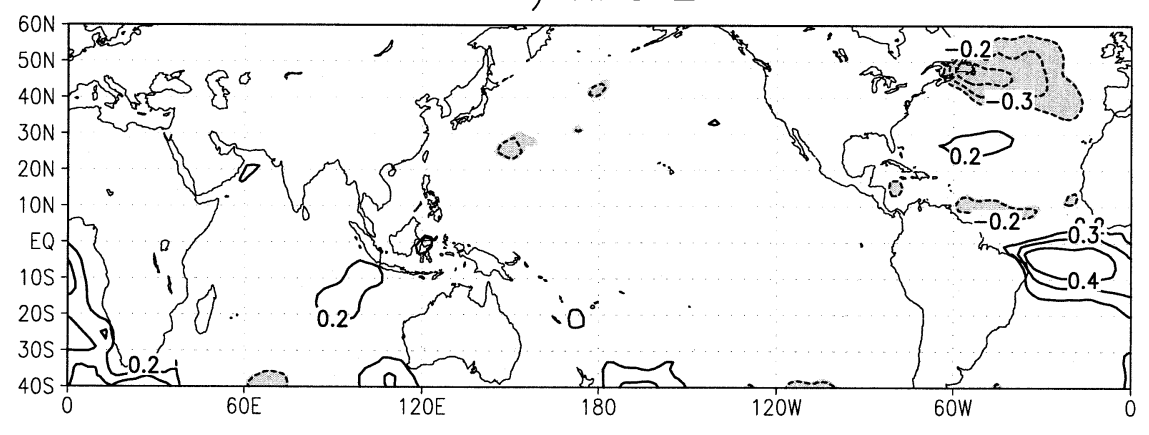

c) $\mathrm{RPC} 4$

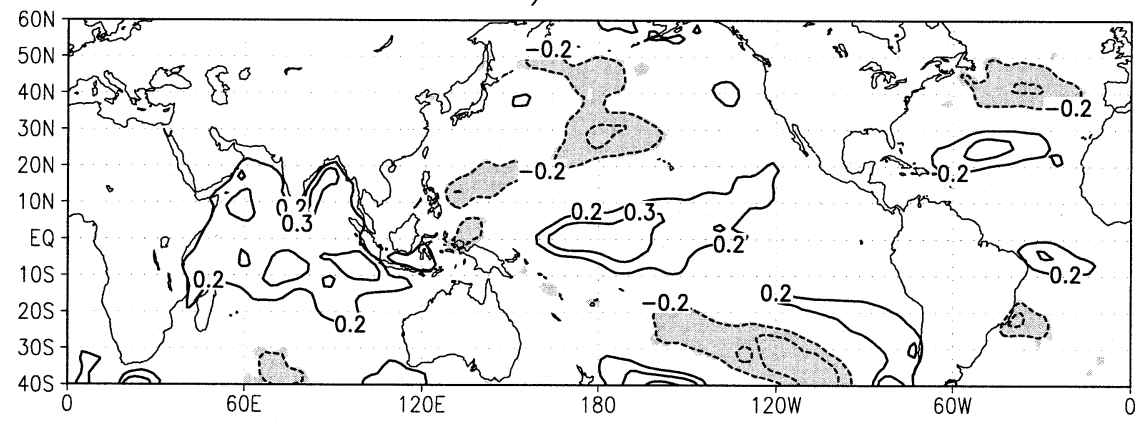

FIG. 4. Correlation between seasonal mean SSTAs and (a) RPC 1, (b) RPC 2, (c) RPC 4 for DJF. Contour interval is 0.1. Contours with values less than 0.2 are omitted. Negative values are shaded.

nificance was determined by the Student's t-test and each event is considered as 1 degree of freedom. The dominant regimes are described below.

\section{a. Pacific influence-ENSO}

REOF 1 (Fig. 2a) explains about $12 \%$ of the total variance. It is also the first unrotated EOF. It has negative loadings over the northern South America centered at $\left(2.5^{\circ} \mathrm{N}, 60^{\circ} \mathrm{W}\right)$, and positive loadings over southern Brazil centered at $\left(15^{\circ} \mathrm{N}, 45^{\circ} \mathrm{W}\right)$, and the subtropical plains at $25^{\circ}-35^{\circ} \mathrm{S}$. A similar pattern has been identified as the response to ENSO (Ropelewski and Halpert 1987, 1989; Kiladis and Diaz 1989) and this is confirmed by the correlation with SSTAs (Fig. 4a). It shows positive SSTAs extending from the eastern Pacific to the central Pacific. Positive correlations are also found over the Indian Ocean, the west coast of North America, and the tropical North Atlantic. Negative correlations exhibit a horseshoe pattern extending into the North and the South Pacific. During strong warm ENSO events like 1958, 1968, 1973, 1983, 1992, 1995, and 1998, RPC 1 was positive; and during strong cold events like 1951, 1956, 1971, 1974, 1976, 1989, RPC 1 was negative (Fig. $3 a)$. The correlation between RPC 1 and the Niño-3.4 index $\left(5^{\circ} \mathrm{N}-5^{\circ} \mathrm{S}, 170^{\circ}-120^{\circ} \mathrm{W}\right)$ for summer (DJF) is 0.81 and the correlation between RPC 1 and the Niño-3 index $\left(5^{\circ} \mathrm{N}-5^{\circ} \mathrm{S}, 150^{\circ}-90^{\circ} \mathrm{W}\right)$ for summer is 0.78 . They are 
statistically significant at the $95 \%$ level. In addition to interannual variability, RPC 1 also shows decadal variations. RPC 1 was largely positive during 1957-66. It decreased during the decade of 1967-76 and reached a minimum in 1976. After that, RPC 1 increased again, with more positive than negative values. These variations are similar to the ones for SSTAs in the central Pacific reported by Trenberth (1990) and Zhang et al. (1997).

The correlations between RPC 1 with SSTAs for one season before and one season after are similar to the correlation map for DJF, but values are slightly weaker (not shown). Monthly precipitation anomalies based on the RPC 1 events for DJF (Fig. 5) for warm ENSO (positive RPC 1) exhibit different seasonal evolution than those for cold ENSO events (negative RPC 1). For cold ENSO years, dry conditions over southeast South America centered at $\left(30^{\circ} \mathrm{S}, 55^{\circ} \mathrm{W}\right)$, and wet conditions over the northwest corner of the continent are found in October and persist through February (shown here only through December). Wet anomalies are found in October over the Brazilian highlands $\left(15^{\circ} \mathrm{S}, 45^{\circ} \mathrm{W}\right)$ moving northward with time. A transition to a negative anomaly over the highlands occurs in December. The pattern for warm ENSO events is more stationary, with positive rainfall anomalies over southeast South America centered near $30^{\circ} \mathrm{S}, 55^{\circ} \mathrm{W}$, and negative anomalies over northern South America persisting from November to March (shown here only through December). The persistence of the north-south dipole is consistent with the correlation between the Southern Oscillation index and rainfall by Trenberth and Caron (2000).

The composite difference of $200-\mathrm{hPa}$ streamfunction anomalies with zonal means removed shows a typical response to ENSO (Fig. 5g). It shows a dipole straddling the equator in the Pacific and another dipole with a sign reversal extending from the eastern Pacific to the Atlantic. The dipole straddling the equator over the central equatorial Pacific is consistent with anomalous warming centers (Rasmusson and Mo 1993; Lau and Zhou 1999). It also implies rising motion over the heated region in the central Pacific and compensating descending motion over tropical South America in agreement with rainfall deficits there.

In the Southern Hemisphere, it shows a wave train extending from the area of convection downstream. It is in phase with the Pacific South American (PSA 1) wave train (Karoly 1989). The mean circulation during the austral summer is conducive to tropical extratropical connection (Berbery and Nogués-Paegle 1993) and Rossby wave propagation. This is different from what is found during the boreal summer where these connections are best established during winter. As noted by Mo (2000), Mo and Nogués-Paegle (2001), Karoly (1989), and Karoly et al. (1996), the PSA 1 teleconnection pattern responds to the changes of SSTAs over the central Pacific due to both ENSO and long-term decadal variations. The PSA 1 wave train is linked to rainfall pattern REOF 1 . Therefore, RPC 1 has similar decadal variations as those of the Pacific SSTAs. The wave pattern shows low pressure in the eastern Pacific at about $20^{\circ} \mathrm{S}$. At low levels (not shown), there is an increased pressure gradient between the Chaco low and the Atlantic subtropical high, indicating a westward displacement and strengthening of the easterly flow from the northern branch of the Atlantic subtropical high. This contributes to an increased moisture supply over eastern Brazil and increases precipitation there. The low-level flow is deflected by the Andes and it contributes to the rainfall maximum over central Argentina.

\section{b. Atlantic influence}

REOF 2 (Fig. 2b), which explains about $10.8 \%$ of the variance shows positive loadings over northeast Brazil centered at $\left(0^{\circ}, 50^{\circ} \mathrm{W}\right)$ and negative loadings over Colombia and Peru. There is a weak negative center at $25^{\circ}-30^{\circ} \mathrm{S}$ south of the positive center. This feature is more clearly shown on the rainfall composite based on gauge data (Fig. 6a). The composite of rainfall for one season after (MAM) based on the RPC 2 events for DJF (Fig. 6d) shows the positive center at the same location consistent with findings of Namias (1972) that drought or wetness over northern Brazil usually persists from summer to fall. The negative center over Peru persists, but the southern center is no longer statistically significant.

The evolution of rainfall over northeast Brazil can be better described by the pentad means (Fig. 7a) from late July to the end of May of the following year. The raining season over that area lasts from December to the end of April. In general, the early start of the summer rainfall season is conducive to a wet season. For example, in wet years like 1984/85, 1989/90, and 1993/94, rainfall started early in late August and in dry years like 1980/ $81,1982 / 83$, and 1986/87, rainfall did not start until early October.

The precursor signal to REOF 2 can be found over the south tropical Atlantic (STA) as indicated by the correlation between RPC 2 (Fig. 3b) and SSTAs during SON (Fig. 7b). There is no signal over the north tropical Atlantic (NTA) during SON. For DJF, the correlation with SSTAs (Fig. 4b) shows the strongest correlation over the STA. Negative correlations extend from the coast of North America at $50^{\circ} \mathrm{N}$ into the North Atlantic. The weak negative correlations over the NTA are only statistically significant at the $90 \%$ level. There is no direct Pacific influence in DJF. For MAM, the strongest rainfall signal is located over northeast Brazil (Fig. 6d) and the associated SSTA pattern shows an alternating band of positive and negative anomalies in the Atlantic (Fig. 7c). The negative correlations over the central Pacific indicate the ENSO signal. Findings here agree with those of Uvo et al. (1998). They examined the relationship between rainfall over northeast Brazil and 


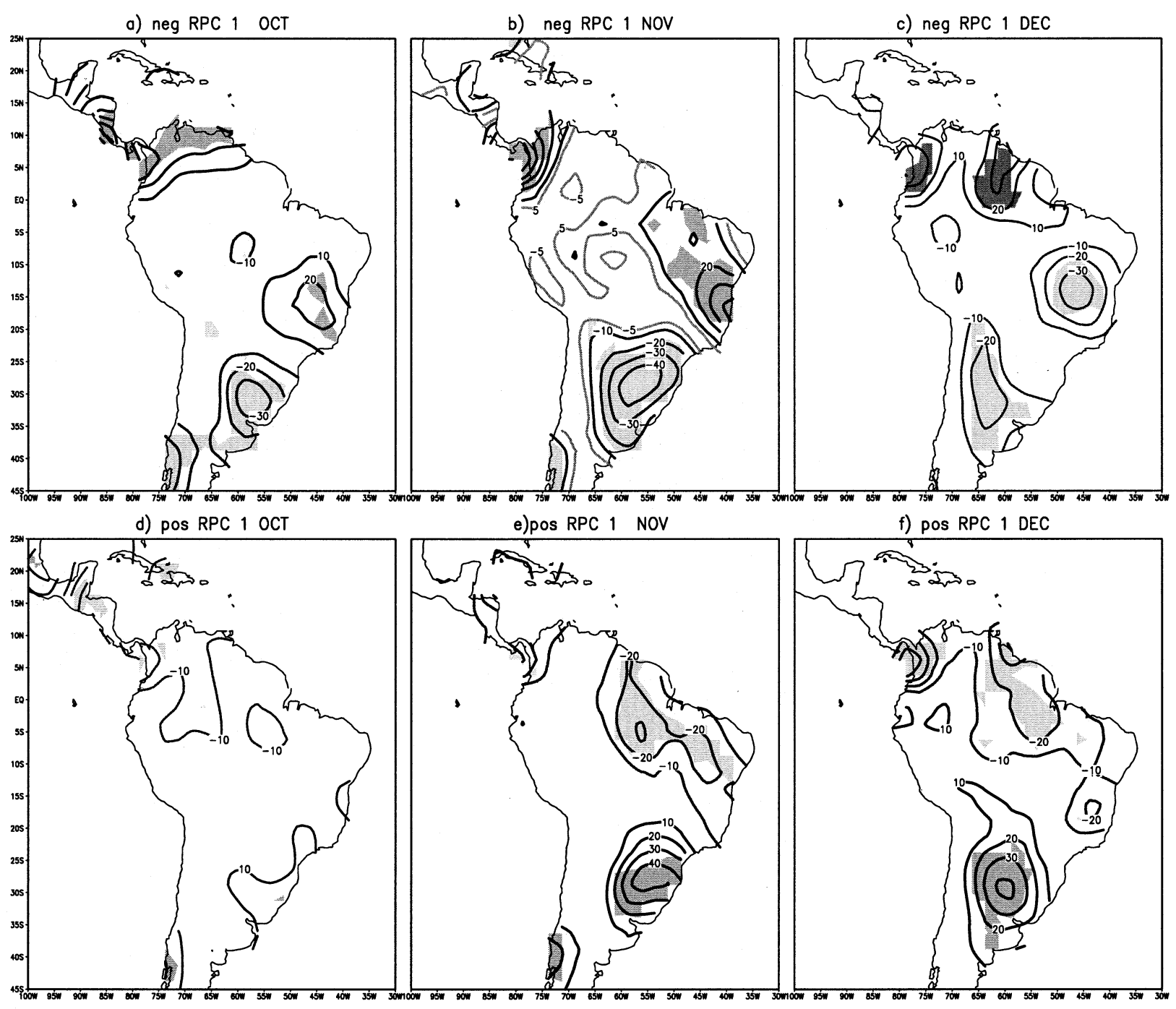

g) psi200 warm-cold djf

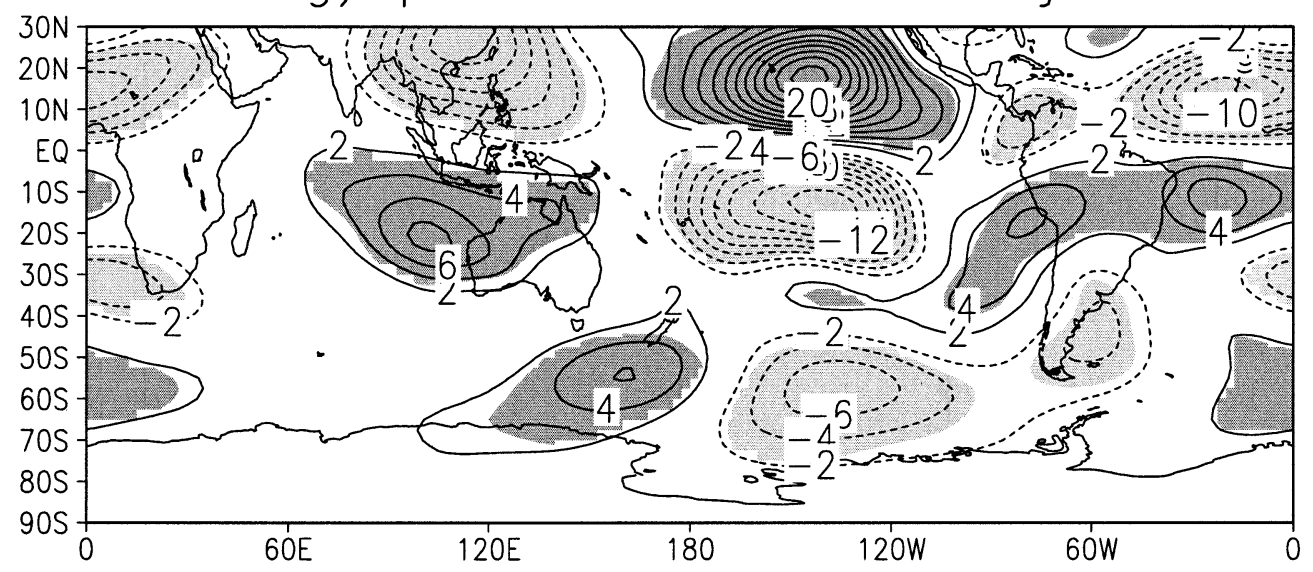


a) RPC 2 DJF

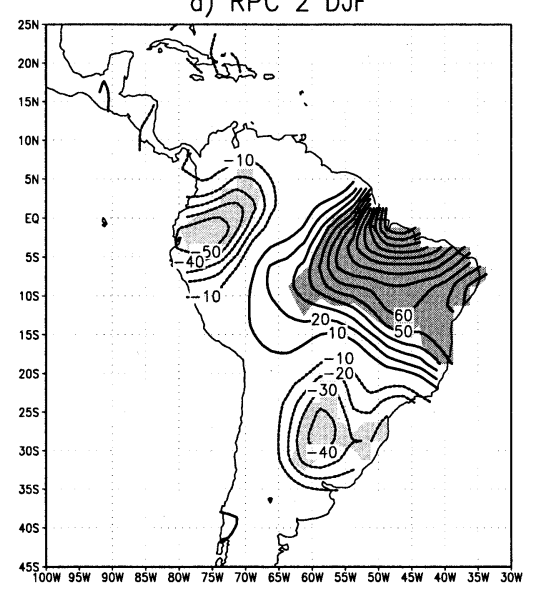

d) RPC 2 MAM

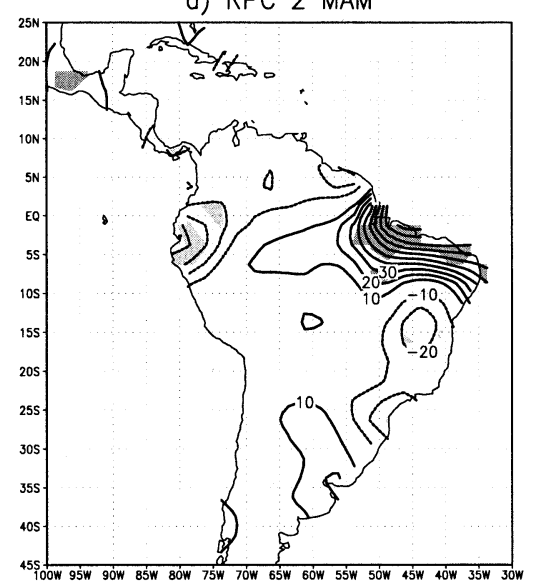

b) DJF STA

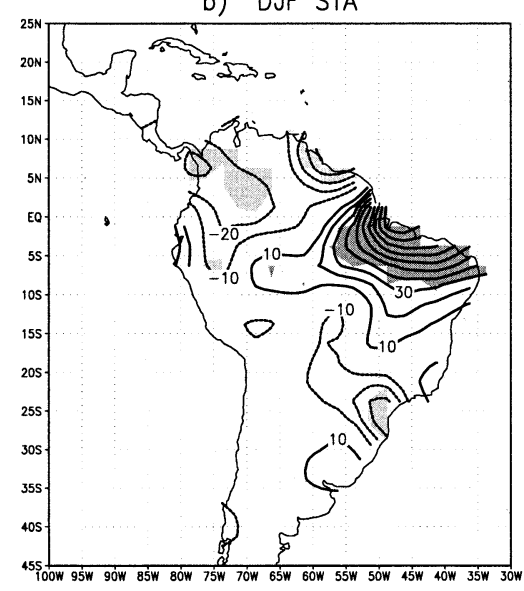

e) STA MAM

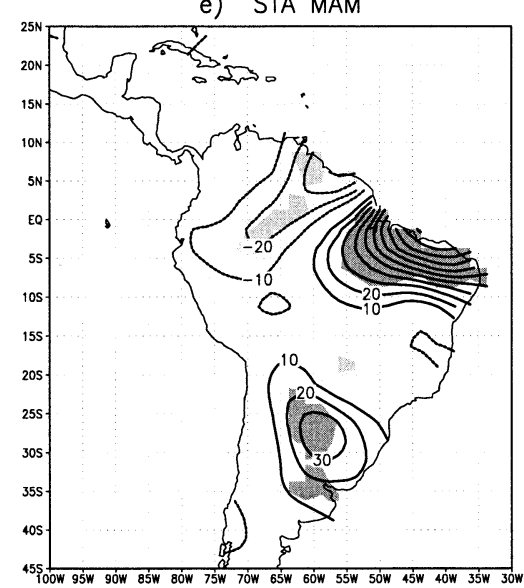

c) DJF NTA
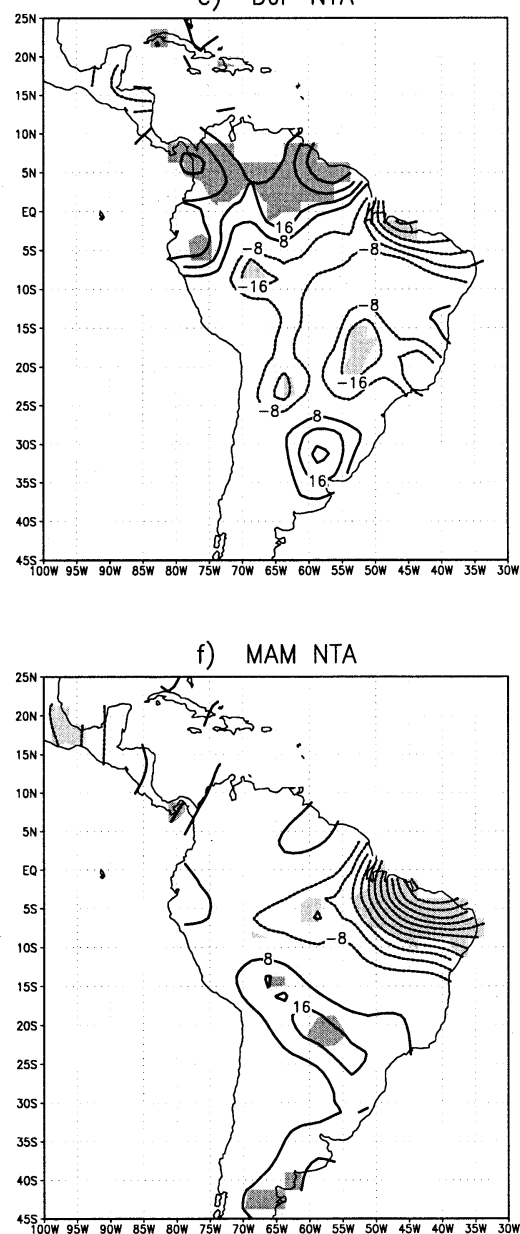

FIG. 6. Composite difference of (a) DJF mean precipitation between positive and negative events based on RPC 2 (DJF) based on the gauge dataset. Contour interval is $10 \mathrm{~mm} \mathrm{month}^{-1}$. Zero contours are omitted. Areas where positive (negative) values are statistically significant at the 95\% level are shaded dark (light); (b) same as (a), but based on the STA index; (c) same as (a), but based on the NTA index, contour interval is $8 \mathrm{~mm}$ month $^{-1}$; (d) same as (a), but for MAM; (e) same as (b), but for MAM; and (f) same as (c), but for MAM.

SSTAs. They found that the influences of SSTAs from both the Pacific and the Atlantic are strongest during April and May.

This tropical SSTA dipole pattern has been linked to rainfall over northern Brazil by Moura and Shukla (1981) and Nobre and Shukla (1996). However, Enfield et al. (1999) and Mo and Hakkinen (2001) found no statistically significant correlations between SSTAs north and south of the equator in the Atlantic on the interannual timescales. Hastenrath and Greischar (1993) and Uvo et al. (1998) suggested that the gradient of SSTAs between the North and South Atlantic is the key element associated with rainfall, rather than the dipole itself. In the next section, we show that large SSTAs over the STA and NTA alone can impact rainfall over northeast Brazil due to the shift of the ITCZ. The influence of the SST gradient to rainfall is limited to northeast Brazil. Elsewhere in South America, the influences of SSTAs over the NTA and the STA on rainfall are not mirror images of each other.

$\leftarrow$

FIG. 5. Composite of (a) Oct, (b) Nov, (c) Dec rainfall anomalies based on negative RPC 1 (Fig. 3a) and composite of (d) Oct, (e) Nov, and (f) Dec rainfall anomalies based on positive RPC 1 . Composites are based on the gauge rainfall dataset. Contour interval is 10 mm month $^{-1}$. Zero contours are omitted. Contours -5 and $5 \mathrm{~mm}$ month ${ }^{-1}$ are added for (b). Areas where positive (negative) values are statistically significant at the $95 \%$ level are shaded dark (light). (g) Composite difference of the 200-hPa streamfunction with zonal means removed between positive and negative RPC 1 . Contour interval is $2 \times 10^{+6} \mathrm{~m} \mathrm{~s}^{-2}$. Contours $-1 \times 10^{+6} \mathrm{~m} \mathrm{~s}^{-2}$ and $1 \times 10^{+6} \mathrm{~m} \mathrm{~s}{ }^{-2}$ are added. Areas where positive (negative) values are statistically significant at the $95 \%$ level are shaded dark (light). 


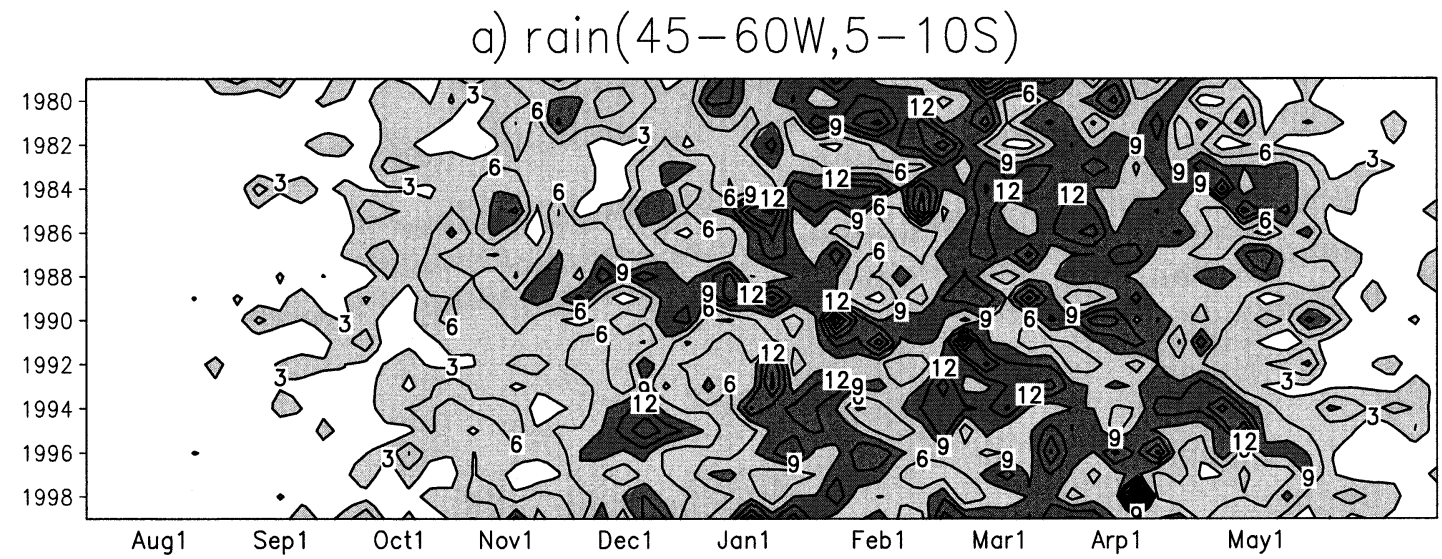

b) $\operatorname{corr}(r p c 2, s s t) \mathrm{SON}$
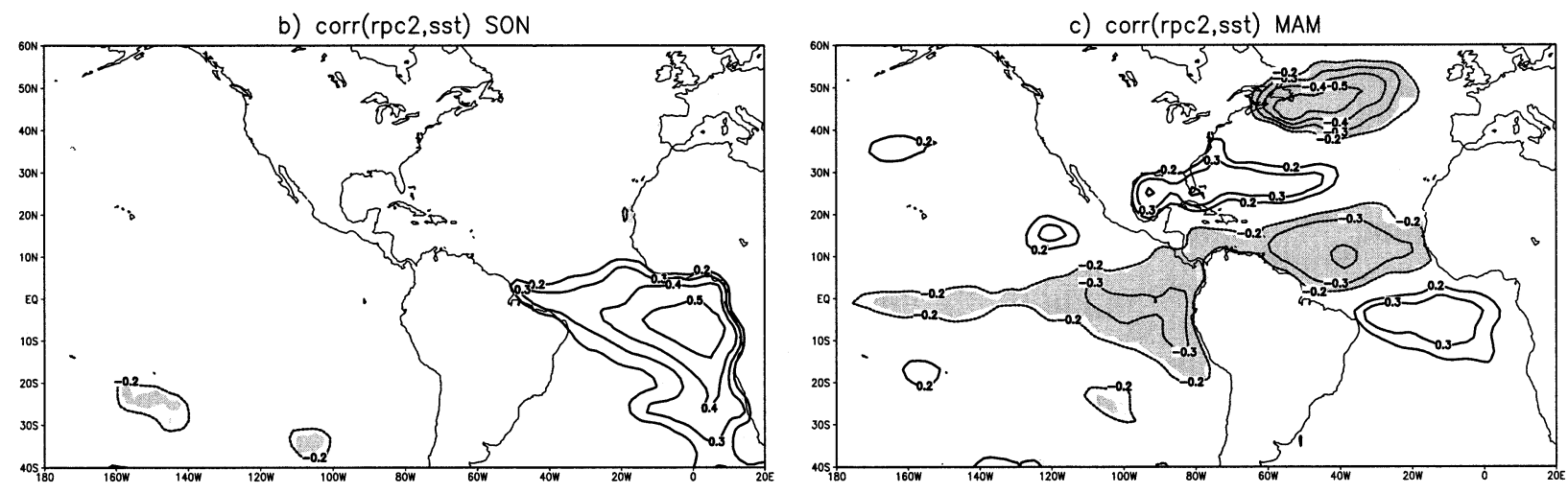

FIG. 7. (a) Pentad mean rainfall averaged over northeast Brazil $\left(5^{\circ}-10^{\circ} \mathrm{S}, 45^{\circ}-60^{\circ} \mathrm{W}\right)$. Areas where values are greater than $3 \mathrm{~mm}$ day ${ }^{-1}$ $\left(9 \mathrm{~mm}\right.$ day $^{-1}$ ) are shaded light (dark), (b) correlation between SSTAs and RPC 2 for SON and (c) same as (b), but for MAM. Contour interval is 0.1 . Contours with values less than 0.2 are omitted. Negative values are shaded.

1) ASSOciation With SSTAS OVER THE TROPICAL SOUTH AND NORTH ATLANTIC

The south tropical Atlantic and north tropical Atlantic indices were formed by averaging SSTAs over the STA $\left(5^{\circ}-15^{\circ} \mathrm{S}, 15^{\circ} \mathrm{W}-5^{\circ} \mathrm{E}\right)$ and the NTA $\left(5^{\circ}-15^{\circ} \mathrm{N}, 40^{\circ}-\right.$ $20^{\circ} \mathrm{W}$ ), respectively. The two areas are located within the trade wind regimes of the southern and northern tropical Atlantic, respectively (Enfield et al. 1999). Composite differences between the positive and negative STA and NTA events (Figs. $6 \mathrm{~b}$ and $6 \mathrm{c}$ ) are made from unfiltered data. They show the dipole between rainfall anomalies over northeastern Brazil and Colombia and Venezuela for DJF with a sign reversal. The center along the coast at $25^{\circ}-30^{\circ} \mathrm{S}$ only appears in the composite based on the STA (Fig. 6b). Negative anomalies shift more inland to $20^{\circ} \mathrm{S}, 55^{\circ} \mathrm{W}$ for the NTA composite. This may explain weak correlations between RPC 2 and the NTA.

For MAM, the rainfall anomalies over northeast Brazil persist for both the STA and the NTA composites (Figs. 6e and 6f). Negative anomalies over Colombia are no longer there. There are weak negative anomalies over Venezuela and positive anomalies over the southern plains for the STA.

The composite differences of the vertically integrated moisture flux and its divergence, $D(Q)$, between positive and negative events based on RPC 2, NTA, and STA are given in Fig. 8. The composites based on the NTA (Fig. 8c) are presented with a sign reversal for comparison with the composites based on the STA (Fig. 8b). They all show enhanced moisture flux convergence over central and eastern tropical South America conducive to enhanced rainfall. In general, moisture divergence patterns correspond well with rainfall anomaly composites. Since the STA and NTA indices are not correlated in interannual timescales, results indicate that either strong cold northern or warm southern tropical SST anomalies can modulate the location of the ITCZ and thus precipitation over northeast Brazil. This implies that the SSTA gradient across the equator has impact on rainfall over northeastern Brazil as indicated by Hastenrath and Greischar (1993). However, the moisture flux composites for DJF based on the STA and the NTA are not mirror images of each other. 
a)RPC 2

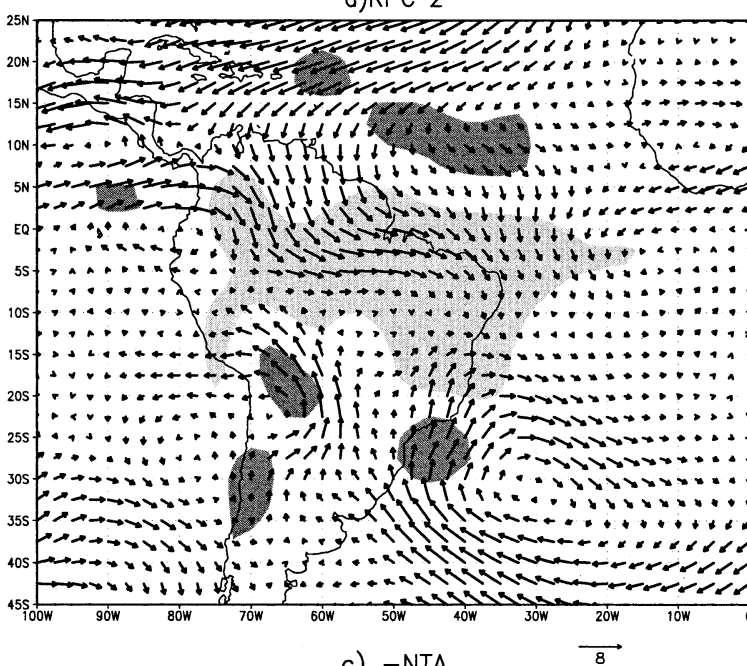

c) $-\mathrm{NTA}$

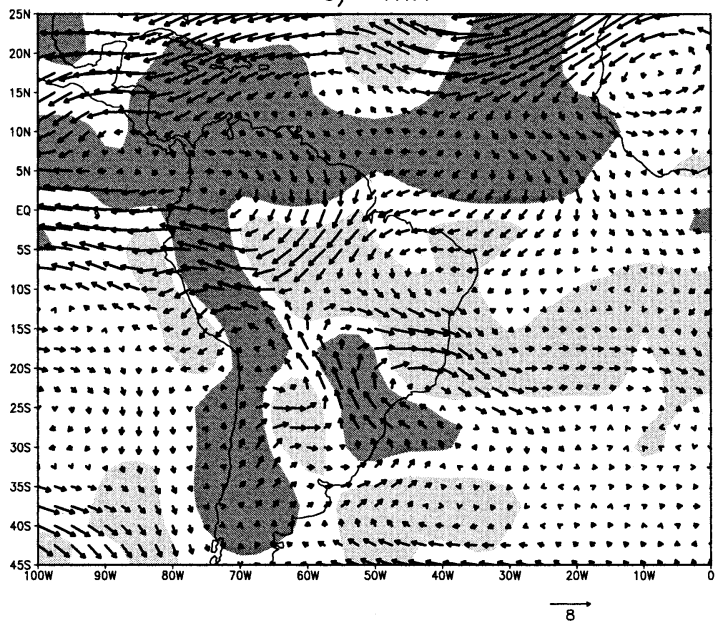

Divergence of moisture flux over the complex Andes orography might not be realistic due to the relatively coarse resolution of the reanalysis. Figure $8 \mathrm{c}$ shows an enhancement of the moisture flux from the North Atlantic to northwestern South America into the South American continent that is not present in Fig. 8b. Such moisture flux enhancement reaches the upper basin of the La Plata River. This basin drains an area extending southward from the Planalto do Matto Grosso (at about $\left.15^{\circ} \mathrm{S}\right)$. It is bounded by the Andes to the west and the Atlantic Ocean to the east. In the decadal timescales, Robertson and Mechoso (1998) have isolated a neardecadal (8-9 yr) component in river flows draining this basin and related it to a similar component in the NAO. Nogués-Paegle et al. (2001) discussed a possible connection between the NAO and the upper La Plata basin through strengthened northeast trades and moisture flux over northern South America, deflected southward by the Andes with moisture convergence and precipitation in a broad band that extends from the deep Tropics to the subtropics of South America. This is in general agreement with the moisture fluxes shown in Fig. 8c.
b)STA

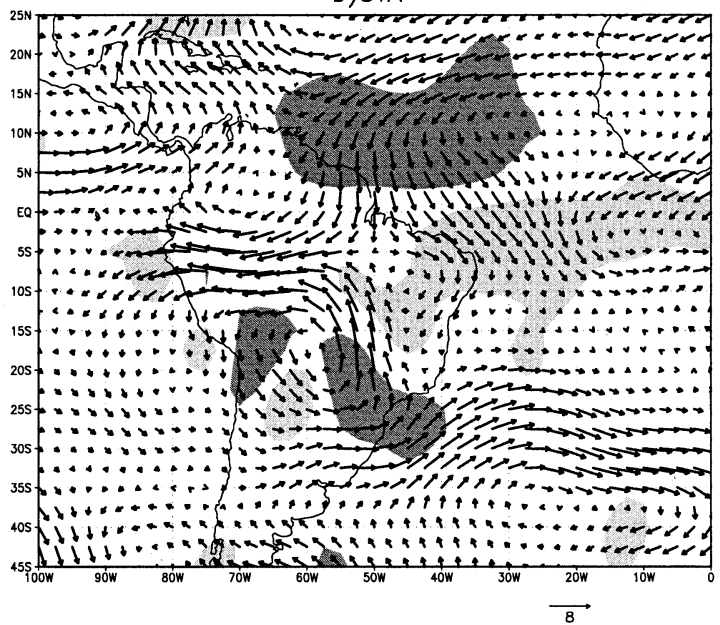

FIG. 8. Composite difference of vertically integrated moisture flux $(q u, q v)$ (vectors) and moisture flux divergence $D(Q)$ (shading) for DJF between positive and negative events based on (a) RPC 2, (b) the STA, and (c) the negative NTA index. Values for $D(Q)$ greater (less) than $0.8 \mathrm{~mm} \mathrm{day}^{-1}$ are shaded dark (light) for (a) and (b) and $0.3 \mathrm{~mm} \mathrm{day}^{-1}$ for (c). The unit for flux is $100 \mathrm{~g}(\mathrm{~cm} \mathrm{~s})^{-1}$.
Rainfall over northeast Brazil is influenced by SSTAs over either the STA or the NTA. Warm SSTAs over the STA responsible for the shift the ITCZ southward and that brings rainfall to northeast Brazil. The situation reverses for the warm NTA conditions. Negative anomalies over Colombia and the southern plains vary with seasons. While the SSTAs over the NTA may influence rainfall over the upper La Plata basin, significant correlations between rainfall and SSTAs over the STA are found over the lower La Plata River basin.

\section{2) NAO INFLUENCE IN THE INTERANNUAL BAND}

In this section, we show that the influence of the NAO on rainfall over South America is weak in the interannual band. There is no direct influence of the NAO on rainfall over South America for DJF and MAM. The NAO can only modulate rainfall indirectly through the NTA in MAM. Since SSTAs over the NTA are also influenced by ENSO, the impact of the NAO on rainfall can only be recognized if the ENSO signal does not interfere. 
a)SLPA DJF

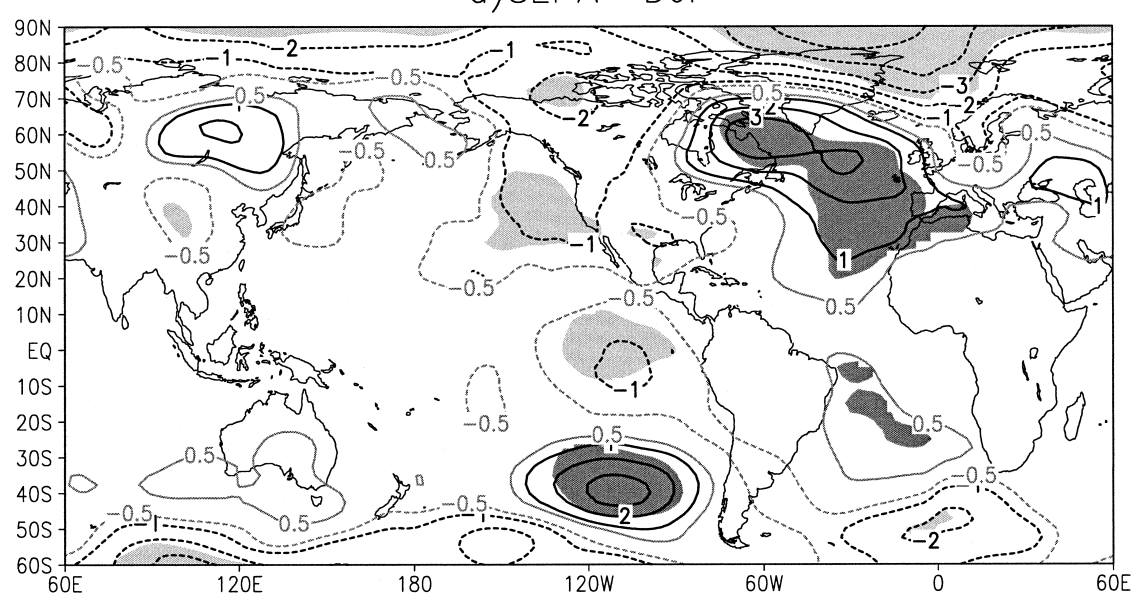

b)SLPA MAM

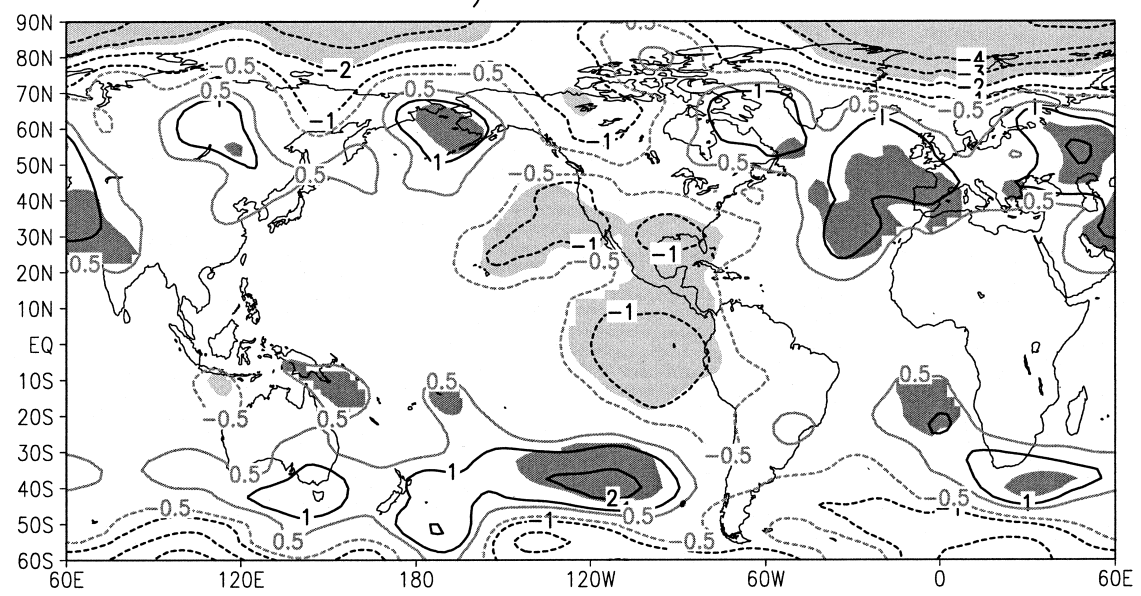

FIG. 9. (a) Composite difference of SLP anomalies for DJF between positive and negative RPC 2 (DJF). Contour interval is $1 \mathrm{hPa}$. Zero contours are omitted. Contours -0.5 and $0.5 \mathrm{hPa}$ are added. Areas where positive (negative) values are statistically significant at the $95 \%$ level are shaded dark (light); (b) same as (a) but for MAM.

The composite differences for the unfiltered sea level pressure anomalies for DJF and MAM (Figs. 9a and 9b) indicate that positive RPC 2 is associated with a dipole in the North Atlantic. For DJF, negative anomalies are located over Greenland and positive anomalies are centered at $45^{\circ}-55^{\circ} \mathrm{N}$. The negative center persists through boreal spring and the positive center moves southward to $30^{\circ}-40^{\circ} \mathrm{N}$, which is the location of the positive center of the NAO (Hurrell 1995; Hurrell and van Loon 1997). Both patterns have a large projection on the NAO and the signal is stronger in MAM consistent with findings of Namias (1972). His composites of 700-hPa height anomalies have a clearer NAO signal in MAM instead of DJF.
The correlations between rainfall from the gauge dataset (Figs. 10a and 10b) and the merged dataset (not shown) and the NAO index for DJF and MAM do not show statistically significant correlations over northeast Brazil, though there are localized regions with significant correlations throughout the continent for both seasons. Lead and lagged correlations between the seasonal mean NAO, NTA, and STA indices and RPC 2 were computed based on the merged dataset. There are 98 years in total. For unfiltered data, the only statistically significant correlation -0.41 is found between the NAO and the NTA index at zero lag for MAM. The correlation at zero lag in DJF is only -0.28 , which is barely statistically significant. Even though SSTAs from the NTA 
a) corr(nao,rain) gauge DJF

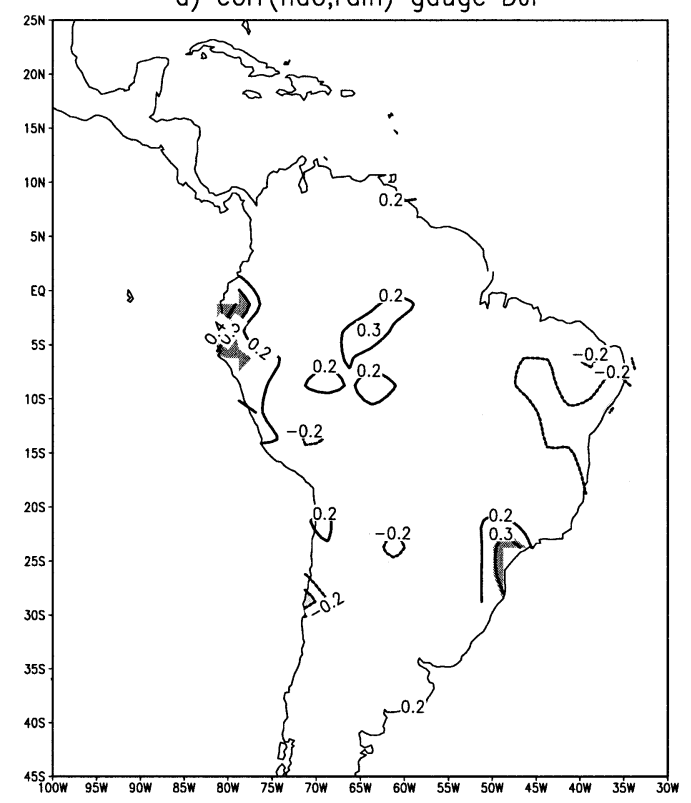

b) corr(nao,rain) gauge MAM

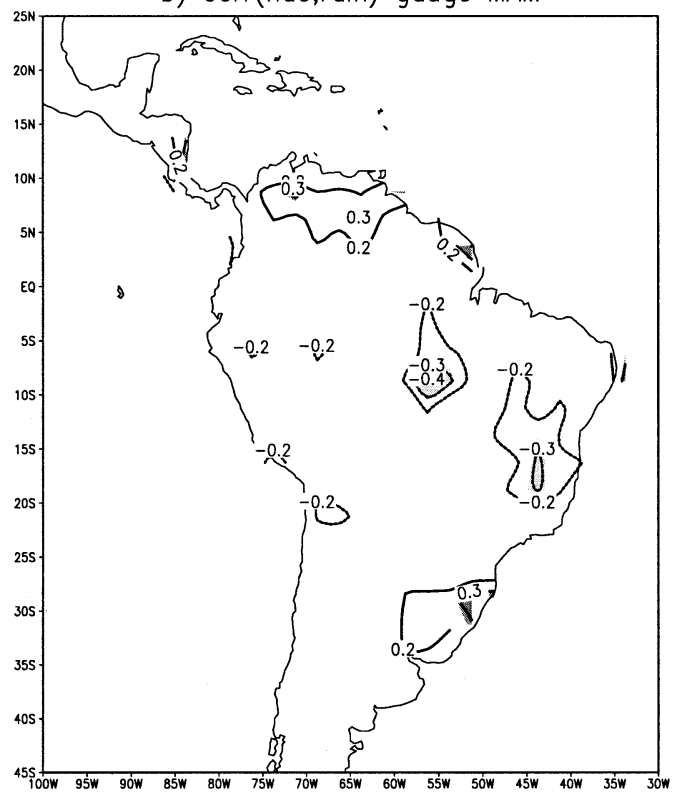

c) composite guage (NAO \&NTA)

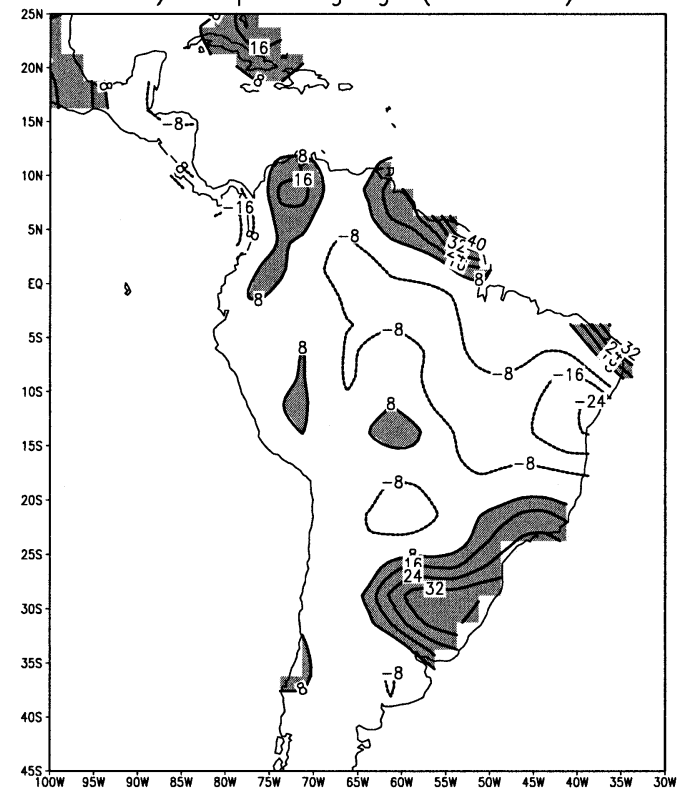

d) composite merged (NAO\& NTA)

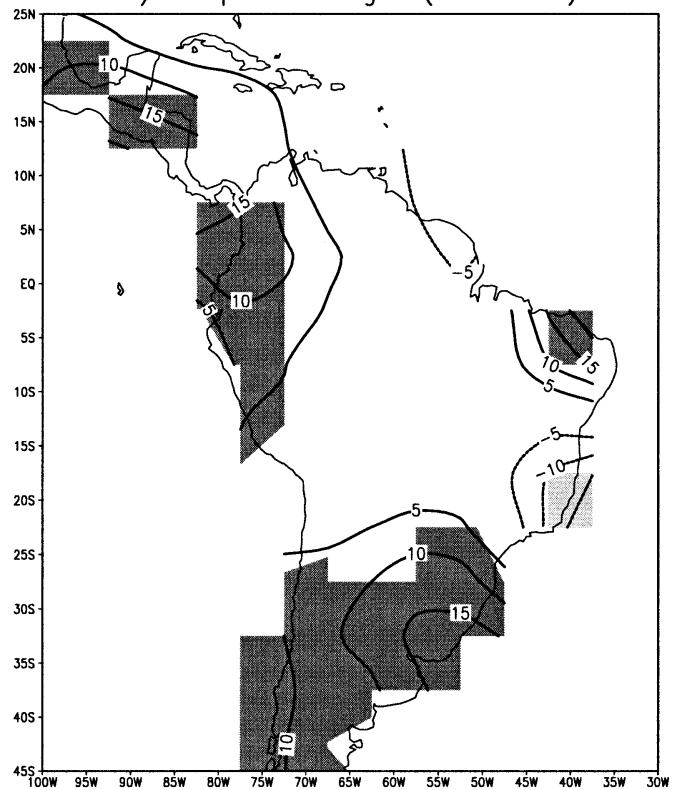

FIG. 10. (a) Correlation between the NAO and rainfall from the gauge dataset for DJF. Contour interval is 0.1. Contours with values less than 0.2 are omitted. Areas where positive (negative) values are statistically significant at the 95\% level are shaded dark (light). (b) Same as (a) but for MAM. (c) Composite rainfall difference between positive and negative NAO-NTA events based on the gauge dataset from 1949 to 1998 for MAM. Contour interval is $8 \mathrm{~mm}$ month ${ }^{-1}$. Zero contours are omitted. Areas where positive (negative) values are statistically significant at the $95 \%$ level are shaded dark (light). (d) Same as (c), but based on the merged dataset from 1901 to 1998. Contours interval is $5 \mathrm{~mm} \mathrm{month}{ }^{-1}$.

can impact rainfall over northeast Brazil, there are no statistically significant correlations between the NAO and RPC 2 for DJF and MAM.

There is no correlation between the NAO and the
STA. Therefore, the NAO can only influence the northeastern Brazil rainfall through SSTAs over the NTA. The SSTAs over the NTA are also modulated by ENSO. Therefore, the influence of the NAO can be realized 
only if the ENSO signal does not interfere. To verify this, we define positive NAO-NTA events when the NAO is above 1 standard deviation and the NTA is below 0.5 standard deviations. The negative events can be identified the same way. From the period from 1950 to 1997 , there were only four positive events (1972, 1976, 1986, and 1994) and five negative events (1953, 1962, 1969, 1996, and 1997). If the period from 1901 to 1997 was considered, there were 11 positive events and 9 negative events. The composite differences between positive and negative NAO-NTA events for the shorter gauge dataset (Fig. 10c) and for the merged dataset (Fig. 10d) show positive anomalies over a small region over the northeastern corner of Brazil and over the subtropical plains centered at $30^{\circ}-35^{\circ} \mathrm{S}, 55^{\circ} \mathrm{W}$. This pattern will have low projection on REOF 2.

We conclude that in the interannual band, the impact of the NAO on rainfall over the northeastern corner of Brazil and the subtropical plains is limited through the influence on SSTAs over the NTA in MAM. The SSTAs over the NTA are also influenced by ENSO (Mo and Hakkinen 2001; Giannini et al. 2000; Enfield and Mayer $1997)$ in MAM. The Pacific SSTAs and the NAO sometime enhance each other and sometime the impact of the NAO is suppressed by the influence from the Pacific. Therefore, the influence of the NAO on rainfall is indirect and depends on the phase of ENSO. In contrast, ENSO can influence rainfall over northeast Brazil directly as indicated by the correlation with SSTAs (Fig. 7c) through the Walker circulation as pointed out by many previous works (Ropelewski and Halpert 1987, 1989; Uvo et al. 1998). It can also influence rainfall indirectly through the SSTAs over the NTA (Giannini et al. 2000; Enfield and Mayer 1997).

\section{3) NAO INFLUENCE ON THE DECADAL TIMESCALES}

In the low-frequency band, the strongest relationship between the NAO and RPC 2 is at lag $3 \mathrm{yr}$ with the NAO leading as indicated by the 5 -yr running means of the NAO at year -3 and RPC 2 (Fig. 11d) for DJF. The two time series follow each other closely except for the periods 1908-13 1947-52, and from 1998 onward. The correlation between them is 0.52 with data from 1900 to 1998 , which is statistically significant at the $95 \%$ level by assuming 1 degree of freedom per 5 yr. The correlation for MAM is only 0.25 , which is not statistically significant.

Unfiltered SSTAs for DJF were regressed against the 5 -yr running means of the NAO index with the NAO leading from lag 0 to lag 5 . At year 0 , strong SSTAs over the North Atlantic are consistent with the NAO signal, but SSTAs over the NTA are weak. Positive SSTAs over the central Pacific are in general associated with dryness over northeast Brazil. Three years later, the regression map against the NAO shows a three-cell pattern with negative SSTAs over the North Atlantic, positive SSTAs off the east coast of North America and negative SSTAs over the NTA. There is no statistically significant SSTAs over the central and eastern Pacific. The SSTA pattern resembles the correlation between RPC 2 and SSTAs (Fig. 4b) except that there is no signal in the South Atlantic. The regression map of precipitation with the NAO leading three years shows a pattern (Fig. 11c) with positive anomalies over northern Brazil and negative anomalies south of the positive anomalies.

The relationship between the NAO and RPC 2 is complex. In the low-frequency band, the NAO leads RPC 2 by $3 \mathrm{yr}$. The influence is strongest in DJF, when the NAO signal is strongest. In the interannual band, there is no statistically significant relationship between the NAO and RPC 2. The SSTAs over the NTA are moderated by SSTAs from the Pacific in addition to the NAO. If signals from the Pacific do not interfere, then the positive (negative) NAO is in favor of positive (negative) rainfall anomalies over the northeastern corner of Brazil.

\section{c. SSTA influence on rainfall over subtropical South America}

REOF 4 shows positive anomalies over Brazil centered at $15^{\circ} \mathrm{S}, 45^{\circ} \mathrm{W}$ and negative anomalies to the south centered at $30^{\circ} \mathrm{S}$ and over northwestern South America centered at $5^{\circ} \mathrm{N}, 70^{\circ} \mathrm{W}$ (Fig. $2 \mathrm{~d}$ ). This pattern modulates the strength of the SACZ and its vicinity. The pattern has some similarity to REOF 2 (Fig. 2b), but anomalies are displaced about $10^{\circ} \mathrm{S}$ and with an additional positive center at $5^{\circ} \mathrm{N}, 70^{\circ} \mathrm{W}$. REOF 2 and REOF 4 jointly describe latitudinal variations of precipitation over central South America. The SSTA pattern associated with REOF 4 (Fig. 4c) shows weak positive values over the central Pacific and the Indian Ocean. These are not presented in correlation with RPC 2 (Fig. 4b). In the Atlantic, Fig. 4c shows alternating positive and negative anomalies similar to the SSTA pattern for RPC 2 (Fig. $4 \mathrm{~b})$, though the correlations are marginally significant.

The correlation between RPC 2 and RPC 4 is 0.4 . RPC 4 (Fig. 3d) followed RPC 2 (Fig. 3b) closely for the period from 1950 to 1962 and then again from 1983 to 1993. The difference between two RPCs was large for the period 1965-70 and from 1978 to 1982. One

FIG. 11. (a) Regression map for SSTAs against the standardized NAO index for DJF. Values were multiplied by 10 before plotting. Contour interval is $0.3^{\circ} \mathrm{C}(\mathrm{std} \mathrm{dev})^{-1}$. Zero contours are omitted. Areas where positive (negative) values are statistically significant at the $95 \%$ level are shaded dark (light). (b) Same as (a) but with the NAO leading 3 yr. (c) Same as (b), but for precipitation anomalies. Contour interval $15 \mathrm{~mm}$ (month std dev) ${ }^{-1}$. (d) Five-yr running mean of normalized RPC 2 and the NAO index leading 3 yr. 

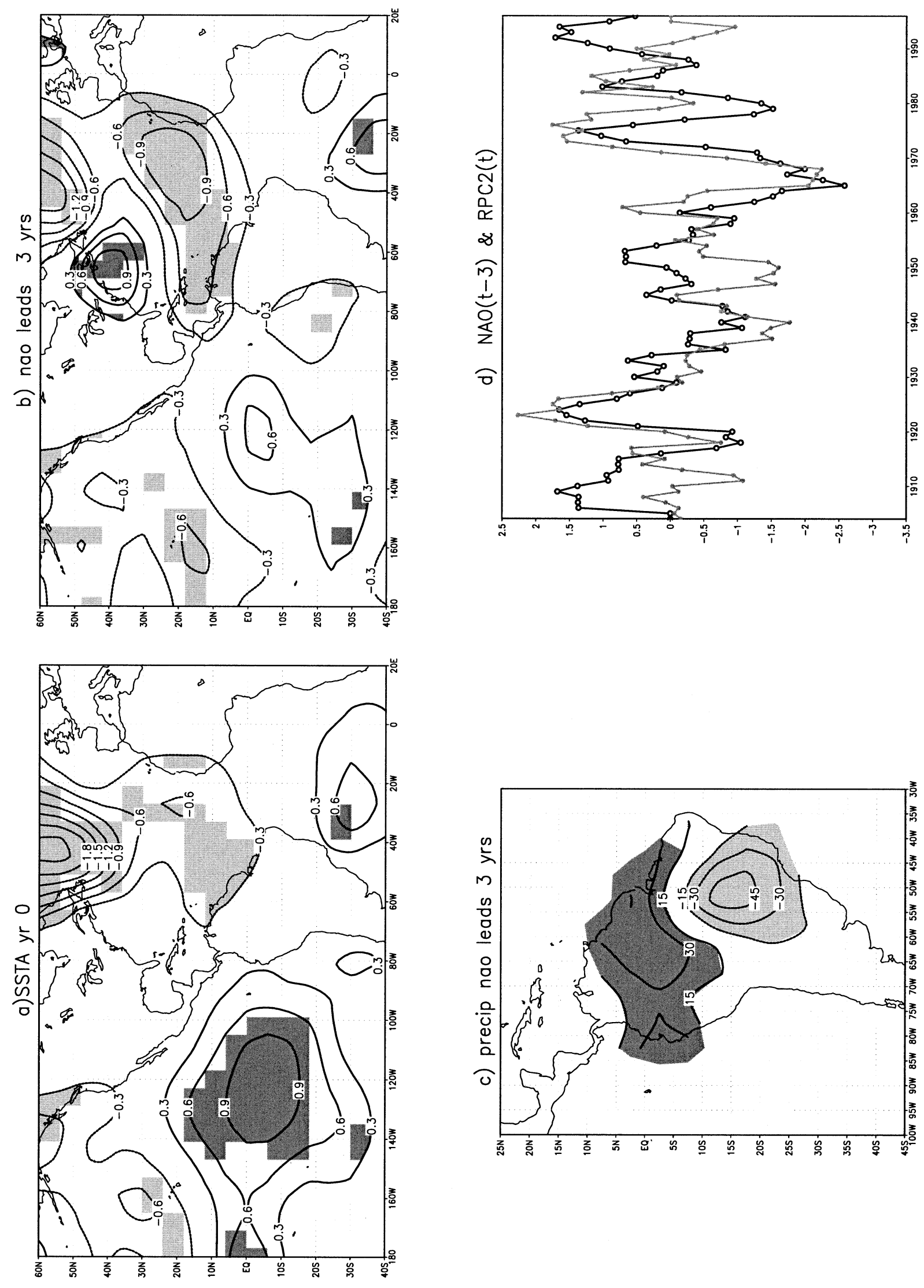

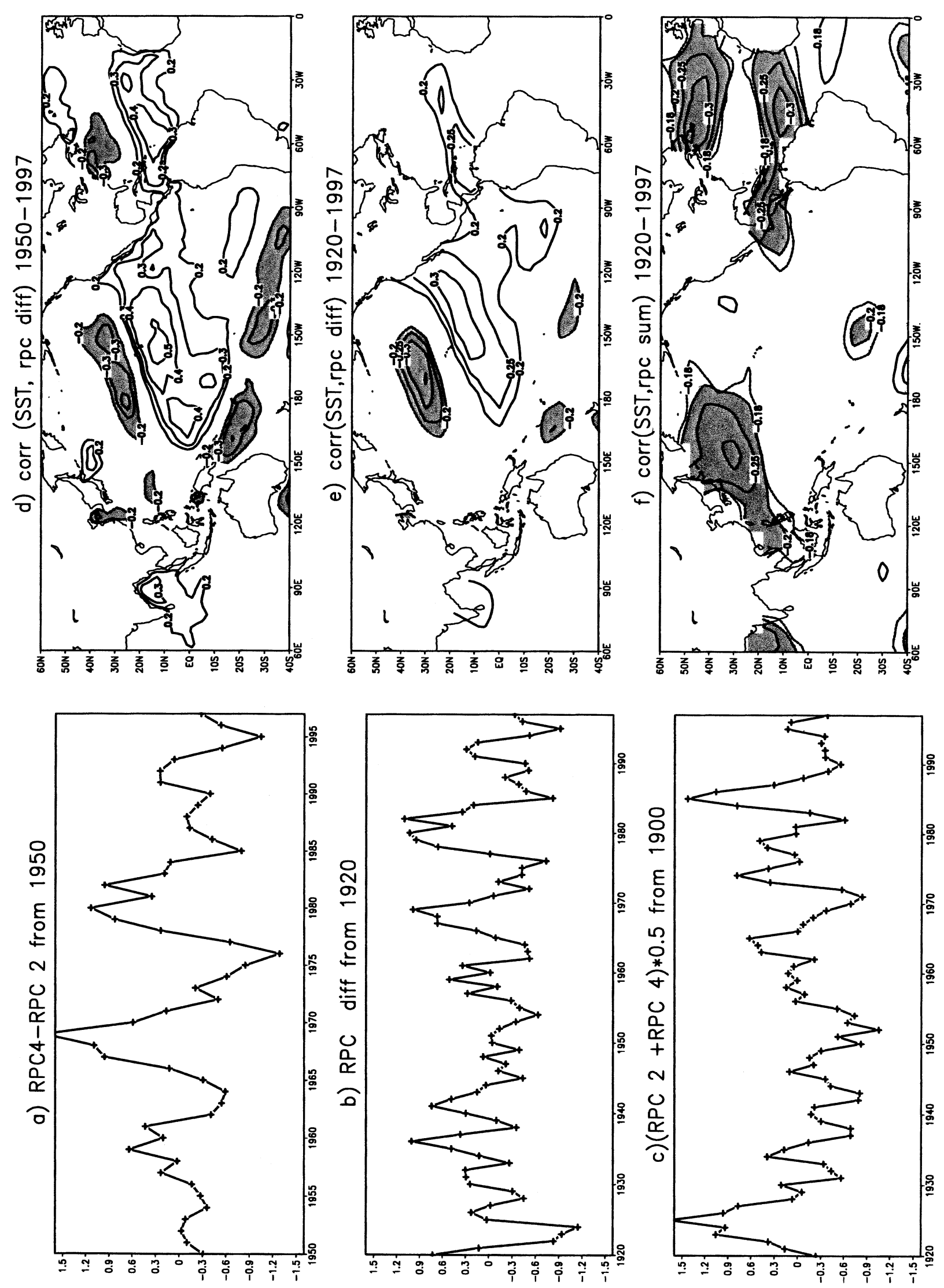
possible explanation is that REOF 4 is influenced by SSTAs from both the Pacific and the Atlantic during this period. Only when the contributions from the Atlantic dominate, two RPCs closely follow each other. To verify this, the difference between normalized RPC 4 and RPC 2 was formed. The 3-yr running means of the RPC difference were plotted for the recent period 1950-97 (Fig. 12a) and the longer period from 1920 to 1997 (Fig. 12b). Each RPC was normalized using the standard deviation calculated for the given period. Figure $12 \mathrm{c}$ shows the sum of normalized RPCs. The smoothed RPC difference and RPC sum were then correlated with global SSTAs. Global SSTAs were not filtered, but a linear trend from 1920 to 1998 was removed at each grid point. The values of correlations need to be greater than $0.22(0.18)$ to be statistically significant at the 95\% (90\%) level for the longer period 1920-97.

The correlation maps with the RPC difference show positive correlations in the central Pacific and negative values in the North Pacific centered at $30^{\circ} \mathrm{N}, 170^{\circ} \mathrm{W}$ (Figs. $12 \mathrm{~d}$ and 12e). There are weak positive correlations over the tropical North Atlantic. Correlations over the North Atlantic for the shorter period (Fig. 12d) are not statistically significant at the $95 \%$ level. Therefore, the SSTAs over the Atlantic are weak in comparison to the correlation map between SSTAs and RPC 2 (Fig. $4 \mathrm{~b})$. In contrast, the correlation with the sum of normalized RPC 2 and RPC 4 shows no signal in the tropical Pacific. In the Atlantic, it shows negative correlations over the North Atlantic and the region extending from Central America to the NTA. The pattern (Fig. 12f) is similar to the correlation map with RPC 2 (Fig. 4b), but correlations in the tropical South Atlantic are only statistically significant at the $90 \%$ level. When RPC 2 and RPC 4 are of the same sign and reenforce each other ( $80 \%$ of the time during the last 50 years) there is a large area $\left(0^{\circ}-20^{\circ} \mathrm{S}, 35^{\circ}-60^{\circ} \mathrm{W}\right)$ of positive rainfall anomaly over northeastern South America including the upper La Plata basin and a precipitation deficit over subtropical South America $\left(25^{\circ}-35^{\circ} \mathrm{S}, 50^{\circ}-60^{\circ} \mathrm{W}\right)$ including the lower La Plata basin. Findings are consistent with Robertson and Mechoso (2000). They identified a 15 -yr out-of-phase component in tributary to the upper and lower La Plata basin.

RPC 4 (Fig. 3d) as well as the sums and differences from Figs. 12b and 12c suggest a lengthening of interdecadal contributions from the mid-1950s to the present. The only period that RPC 2 and 4 had opposite signs (RPC 4 positive and RPC 2 negative, Figs. 3b and 3d) for 3 consecutive years was 1968-70. This, together with the low amplitudes of both modes from the late 1950s to the mid-1960s (Figs. 4b,d and 12c) is indicative of several years of low precipitation over central South America. An independent corroboration of these extended drought conditions is provided by the level and extent of the Pantanal, South American wetlands, which showed anomalously low values during the decade from 1964 to 1973. Estimates by Hamilton et al. (1996) indicate maximum water levels at $30 \%$ of the average for the subsequent decades. The RPC associated with the ENSO-like pattern (Mo 2000, her Fig. 5d) was negative from 1962 to 1975 . This favors dry conditions over the southeastern half of the continent according to REOF 1 (Fig. 2a). The weakness of the Atlantic forcing and the negative phase of the ENSO-like mode imply that the changes in the Pacific SSTs may contribute to the anomalous dry conditions over the Pantanal. The Pantanal returned to normal conditions in the mid-1970s when warming started in the Pacific.

\section{Conclusions}

Precipitation regimes in South America in both interannual and decadal bands are examined based on rotated EOF analysis. The influence of SSTAs is quantified through correlations of SSTAs with the principal components associated with REOFs. The dominant mode is associated with ENSO. It has negative loadings over the northern South America and positive loadings over southern Brazil and the subtropical plains at $25^{\circ}-35^{\circ} \mathrm{S}$. Results are consistent with those of other studies that suggest that negative rainfall anomalies in northern South America during warm ENSO events are due to the Walker circulation while in the area south of $25^{\circ} \mathrm{S}$, rainfall anomalies are associated with the PSA 1 wave train extending from the convective area into South America. In addition to ENSO, low-frequency variations of SSTAs in the Pacific such as the ENSO-like decadal pattern (Garreaud and Battisti 1999; Mo 2000) can also excite the PSA 1 wave train, which in turn excites a rainfall pattern like REOF 1 over South America.

REOF 2 is influenced by the Atlantic SSTAs, which shows positive loadings over northeast Brazil and negative loadings over Colombia and Peru and the subtropical plains. In the interannual band, this pattern is associated with positive SSTAs over the tropical South Atlantic. The impact of the SSTAs over the NTA is limited to a small northeastern corner of Brazil. For MAM, both the north and south tropical Atlantic SSTs are associated with a shift of the ITCZ and therefore

$\leftarrow$

FIG. 12. (a) The 3-yr running means of the difference between normalized RPC 4 and RPC 2 (RPC 4 - RPC 2) for the period 1950-97. (b) Same as (a), but for the period from 1920 to 1997. (c) Same as (b), but for the sum of normalized RPC 2 and RPC 4. (d) Correlation between DJF mean SSTAs with the RPC difference from 1950 to 1997 given in (a). Values below 0.2 are omitted. Negative values are shaded. (e) Same as (d), but with the RPC difference from 1920 to 1997 given in (b); and (f) same as (d), but for the average of normalized RPC 2 and RPC 4 given in (c). 
they modulate northern Brazil rainfall. Except for northern Brazil, the influences of the STA and the NTA on rainfall over South America are not mirror images of each other.

In the interannual band, the NAO contributes to rainfall over the northeastern corner of Brazil and subtropical plains in MAM only if SSTAs over the NTA are dominated by the NAO. The contribution of the NAO is limited in comparison to the contribution from ENSO. ENSO can impact rainfall over northeast Brazil directly through the Walker circulation associated with the ENSO convection pattern and also indirectly through the SSTAs over the NTA (Giannini et al. 2000; Uvo et al. 1998). In the low-frequency band, the NAO leads RPC 2 by 3 years. Recently, the modeling experiments by Robertson et al. (2000) show that the NAO can be excited by SSTAs in the tropical and subtropical Atlantic. Nevertheless, no statistically significant correlations are found here between the NAO and the STA.

Both the Pacific and the Atlantic SSTAs have an impact on REOF 4. This pattern shows positive anomalies over Brazil centered at $15^{\circ} \mathrm{S}$ and negative anomalies to the south and over northwestern South America (Fig. $2 d)$. The pattern is similar to REOF 2 , but anomalies are displaced about $10^{\circ} \mathrm{S}$ and there is also an additional center at about $30^{\circ} \mathrm{S}$. RPC 4 followed RPC 2 closely for the period from 1950 to 1962 and then again from 1983 to 1993 . REOF 4 is influenced by SSTAs from both the Pacific and the Atlantic, with a dominant Atlantic/Pacific influence when the two modes are in/out of phase. Precipitation over the upper basin of the La Plata River basin is modulated by both RPC 2 and RPC 4. The amplitude of these two modes was small during the mid-1950s to the mid-1960s and they were out of phase from 1968 to 1970, resulting in persistent dry conditions over this region. An independent corroboration of dry conditions over the region is provided by the level and extent of the Pantanal, South American wetlands, which show anomalously low values during the decade from 1964 to 1973.

Acknowledgments. This work is partially supported by the GMAP/NASA Grant 291-01-91-25.

\section{REFERENCES}

Aceituno, P. F., 1988: On the functioning of the Southern Oscillation in the South American sector. Part I: Surface climate. Mon. Wea. Rev., 116, 505-524.

Barnston, A. G., and R. E. Livezey, 1987: Classification, seasonality and persistence of low-frequency atmospheric circulation patterns. Mon. Wea. Rev., 115, 1083-1126.

Barros, V., M. Gonzalez, B. Liebmann, and I. Camilloni, 1999: Influence of the South Atlantic Convergence Zone and South Atlantic sea surface temperatures on interannual summer rainfall variability in Southeastern South America. Theor. Appl. Climatol., 67, 128-133.

Berbery, E. H., and J. Nogués-Paegle, 1993: Intraseasonal interactions between the Tropics and extratropics in the Southern Hemisphere. J. Atmos. Sci., 50, 1950-1965.
Chen, M., P. Xie, J. E. Janowiak, and P. A. Arkin, 2002: Global land precipitation: A 50-yr monthly analysis based on gauge observations. J. Hydrometeor., in press.

Diaz, A. F., C. D. Studzinski, and C. R. Mechoso, 1998: Relationships between precipitation anomalies in Uruguay and southern Brazil and sea surface temperature in the Pacific and Atlantic Oceans. J. Climate, 11, 251-271.

Enfield, D., and D. A. Mayer, 1997: Tropical Atlantic sea surface temperature variability and its relation to El Niño-Southern Oscillation. J. Geophys. Res., 102, 929-945.

_ A. M. Mestas-Nunez, D. A. Mayer, and L. Cid Serano, 1999: How ubiquitous is the dipole relationship in tropical Atlantic sea surface temperatures. J. Geophys. Res., 104, 7841-7848.

Fu, R., B. Zhu, and R. Dickinson, 1999: How do the atmosphere and land surface influence the seasonal changes of convection in tropical Amazon? J. Climate, 12, 1306-1321.

Gandin, L. S., 1965: Objective Analysis of Meteorological Fields. Israel Program for Scientific Translations, $242 \mathrm{pp}$.

Gandu, A. W., and P. L. Silva Dias, 1998: Impact of tropical heat sources on the South American tropospheric upper circulation and subsidence. J. Geophys. Res., 103, 6001-6015.

Garreaud, R. D., and D. S. Battisti, 1999: Interannual and interdecadal (ENSO-like) variability in the Southern Hemisphere tropospheric circulations. J. Climate, 12, 2113-2123.

Giannini, A., Y. Kushnir, and M. A. Cane, 2000: Interannual variability of Caribbean rainfall, ENSO, and the Atlantic Ocean. $J$. Climate, 13, 297-311.

Hamilton, S. K., S. J. Sipel, and J. M. Melack, 1996: Inundation patterns in the Pantanal wetland of South America determined from passive microwave remote sensing. Arch. Hydrobiol., 137, $1-23$.

Hastenrath, S., and L. Heller, 1977: Dynamics of climate hazards in Northeast Brazil. Quart. J. Roy. Meteor. Soc., 103, 77-92.

, and L. Greischar, 1993: Circulation mechanisms related to Northeast Brazil rainfall anomalies. J. Geophys. Res., 98, 50935102 .

Horel, J. D., A. N. Hahmann, and J. E. Geisler, 1989: An investigation of the annual cycle of convective activity over the tropical Americas. J. Climate, 2, 1388-1403.

Hulme, M., 1991: An intercomparison of model and observed global precipitation climatologies. Geophys. Res. Lett., 18, 1715-1718.

Hurrell, J. W., 1995: Decadal trends in the North Atlantic Oscillation: Regional temperature and precipitation. Science, 269, 676-679.

$\ldots$, and H. van Loon, 1997: Decadal variations in climate associated with the NAO. Climatic Change, 36, 301-326.

Janowiak, J. E., and P. P. Xie, 1999: CAMS-OPI a global satelliterain gauge merged product for real time precipitation monitoring applications. J. Climate, 12, 3335-3342.

Kalnay, E., and Coauthors, 1996: The NCEP/NCAR 40-Year Reanalysis Project. Bull. Amer. Meteor. Soc., 77, 437-471.

Karoly, D. J., 1989: Southern Hemisphere circulation features associated with El Niño-Southern Oscillation events. J. Climate, 2, 1239-1251.

— , P. Hope, and P. D. Jones, 1996: Decadal variations for the Southern Hemisphere circulation. J. Climatol., 16, 723-738.

Kiladis, G. N., and H. F. Diaz, 1989: Global climate anomalies associated with extremes in the Southern Oscillation. J. Climate, 2, 1069-1090.

Kousky, V. E., 1979: Frontal influences on northeast Brazil. Mon. Wea. Rev., 107, 1140-1153.

, 1988: Pentad outgoing longwave radiation climatology for the South American sector. Rev. Bras. Meteor., 3, 217-231.

, and C. F. Ropelewski, 1997: The tropospheric seasonally varying mean climate over the Western Hemisphere (1979-1995). NCEP/Climate Prediction Center Atlas 3, NCEP/CPS, 135 pp.

Lau, K.-M., and J. Zhou, 1999: South American summer monsoon of 1997/98 and 1998/99. Proc. 24th Annual Climate Diagnostics and Prediction Workshop, Tucson, AZ, NOAA, 17-20.

Liebmann, B., and J. Marengo, 2001: Interannual variability of the 
rainy season and rainfall in the Brazilian Amazon basin. J. Climate, 14, 4308-4318.

Marengo, J., B. Liebmann, V. E. Kousky, N. P. Filizola, and I. C. Wainer, 2001: Onset and end of the rainy season in the Brazilian Amazon basin. J. Climate, 14, 833-852.

Mo, K. C., 2000: Relationships between low-frequency variability in the Southern Hemisphere and sea surface temperature anomalies. J. Climate, 13, 3599-3610.

- and S. Hakkinen, 2001: Interannual variability of the tropical Atlantic and linkages to the Pacific. J. Climate, 14, 2740-2762. , and J. Nogués-Paegle, 2001: The Pacific-South American modes and their downstream impact. J. Climatol., 21, 12111229 .

Moura, A. D., and J. Shukla, 1981: On the dynamics of drought in Northeast Brazil: Observations, theory and numerical experiments with a general circulation model. J. Atmos. Sci., 38, 26532675.

Namias, J., 1972: Influence of northern hemisphere general circulation on drought in northeast Brazil. Tellus, 24, 336-342.

Nobre, P., and J. Shukla, 1996: Variations of sea surface temperature, wind stress, and rainfall over the tropical Atlantic and South America. J. Climate, 9, 2464-2479.

Nogués-Paegle, J., A. W. Robertson, and R. C. Mechoso, 2001: Relationship between the North Atlantic Oscillation and river flow regimes of South America. Proc. NOAA 25th Annual Climate Diagnostics and Prediction Workshop, New York, NY, NOAA, 234-238.

O'Lenic, E. A., and R. L. Livezey, 1988: Practical considerations in the use of rotated principal component analysis (RPCA) in diagnostic studies of upper-air height fields. Mon. Wea. Rev., 116, $1682-1689$.

Rasmusson, E. M., and K. C. Mo, 1993: Linkages between 200-mb tropical and extratropical circulation anomalies during the 19861989 ENSO cycle. J. Climate, 6, 595-616.

Reynolds, R. W., and T. M. Smith, 1994: Improved global SST analyses using optimum interpolation. J. Climate, 7, 929-948.

Richman, M. B., 1986: Rotation of principal components. J. Climatol., 6, 293-335.

- and P. J. Lamb, 1985: Climatic pattern analysis of three- and seven-day summer rainfall in the central United States: Some methodological considerations and a regionalization. J. Climate Appl. Meteor., 24, 1325-1343.

Robertson, A. W., and C. R. Mechoso, 1998: Interannual and decadal cycles in river flows of southeastern South America. J. Climate, 11, 2570-2581.

and - 2000: Interannual and interdecadal variability of the South Atlantic convergence zone. Mon. Wea. Rev., 128, 2947 2957.

__ _ _ - and Y. J. Kim, 2000: The influence of Atlantic sea surface temperature anomalies on the North Atlantic Oscillations. J. Climate, 13, 122-138.

Ropelewski, C. F., and H. S. Halpert, 1987: Global and regional scale precipitation patterns associated with the El Niño/Southern Oscillation. Mon. Wea. Rev., 115, 1606-1626.

- and _ 1989: Precipitation patterns associated with the high index phase of the Southern Oscillation. J. Climate, 2, 268-284.

- J. E. Janowiak, and M. S. Halpert, 1985: The Climate Anomaly Monitoring System "CAMS." Climate Prediction Center Rep. $38 \mathrm{pp}$.

Rusticucci, M., and O. Penalba, 2000: Interdecadal changes in the precipitation seasonal cycle over southern South America: Relationship with surface temperature. Climate Res., 16, 1-15.

Smith, T. M., R. W. Reynolds, R. E. Livezey, and D. C. Stokes, 1996: Reconstruction of historical sea surface temperatures using empirical orthogonal functions. J. Climate, 9, 1403-1420.

_, R. E. Livezey, and S. S. Shen, 1998: An improved method for analyzing sparse and irregularly distributed SST data on a regular grid: The tropical Pacific Ocean. J. Climate, 11, 1717-1729.

Trenberth, K. E., 1990: Recent observed interdecadal climate changes in the Northern Hemisphere. Bull. Amer. Meteor. Soc., 71, 988 993

_ and J. M. Caron, 2000: The Southern Oscillation revisited: Sea level pressures, surface temperatures, and precipitation. J. Climate, 13, 4358-4365.

Uvo, C., A. A. Repelli, S. E. Zebiak, and Y. Kushnir, 1998: The relationships between tropical Pacific and Atlantic SST and northeast Brazil monthly precipitation. J. Climate, 11, 551-562.

Zhang, Y., J. M. Wallace, and D. S. Battisti, 1997: ENSO-like interdecadal variability: 1900-93. J. Climate, 10, 1004-1020.

Zhou, J., and K.-M. Lau, 2001: Principal modes of interannual and decadal variability of summer rainfall over South America. Int. J. Climatol., 21, 1623-1644. 